\title{
Obelix vs. Asterix: Size of U.S. Commercial Banks and Its Regulatory Challenge
}

\author{
Diego Restrepo-Tobón · Subal C. Kumbhakar • Kai Sun
}

Received: March 14, 2014 / Accepted:

\begin{abstract}
Big banks pose substantial costs to society in the form of increased systemic risk and government bailouts during crises. Should regulations limit the size of banks? To answer this question, regulators need to assess the potential costs of such regulations. If big banks enjoy substantial scale economies, that is, lower average costs as bank size increases, size limit regulations may be inefficient and may reduce social welfare. However, the literature offers conflicting results regarding the existence of economies of scale for the biggest U.S. banks. We contribute to this literature using a novel approach to estimate nonparametric measures of scale economies and total factor productivity (TFP) growth. For U.S. commercial banks, we find that around $73 \%$ of the top one hundred banks, $98 \%$ of medium and small banks, and seven of the top ten biggest banks by asset size exhibit substantial economies of scale. In addition, scale economies contribute positively and significantly to their TFP growth. The existence of substantial scale economies at commercial banks raises an important challenge for regulators to pursue size limit regulations.
\end{abstract}

Keywords bank regulation - economies of scale returns to scale $\cdot$ nonparametric methods

JEL Classification L51 · G21 · G28 · D24 · L25 · C14

\section{Introduction}

After the latest U.S. financial crisis, the optimal size of banks became an important issue for regulators and policymakers. Too-big-to-fail banks seems to enjoy a funding advantage in capital markets

Restrepo-Tobón acknowledges financial support from the Colombian Fulbright Commission; the Colombian Administrative Department of Science, Technology and Innovation (Colciencias); and EAFIT University.

D. Restrepo-Tobón (Corresponding author)

EAFIT University, Carrera 49 \#7 Sur 50, Medellín, Colombia,

E-mail: drestr16@eafit.edu.co

S. Kumbhakar

Binghamton University 4400 Vestal Pkwy E, Binghamton, NY 13902, United States,

University of Stavanger, 4036 Stavanger, Norway,

E-mail: kkar@binghamton.edu

K. Sun

University of Salford, Salford, Greater Manchester, M5 4NT, United Kingdom,

E-mail: ksun1@binghamton.edu 
over smaller banks mostly due to implicit government guarantees (Gandhi and Lustig, Forthcoming). Prominent academicians and policy makers have proposed to break up the biggest banks arguing that they pose substantial costs to society in the form of government bailouts and increased systemic risk. ${ }^{1}$ However, policy proposals to break up or to cap the size of the biggest U.S. banks failed to materialize. A possible explanation for this outcome is that there is no consensus on the desirability or feasibility of capping the size of banks (Stern and Feldman 2009). More recently, the discussion has been reignited and capping the size of banks is again at the center of the regulatory policy debate.

Against this backdrop, the existence of economies of scale for the biggest U.S. banks has become a contentious and important issue. Economies of scale, that is, the existence of lower average costs as firm's size increases, have been at the center of policy analyses in the regulation and deregulation of different industries. ${ }^{2}$ It could be challenging for regulators to promote perfect competition when substantial economies of scale are present (Laudati, 1981). As suggested by Borts (1954), the existence of scale economies may lead regulators to favor the emergence and consolidation of large firms while ensuring that customers are served on reasonable terms - even if new entry and competition in the market is reduced.

Since Williamson $(1968,1977)$ economies of scale underlie almost every aspect of antitrust regulation and constitute the basis for the well-known efficiency defense in mergers. ${ }^{3}$ For instance, a merger that lowers competition may bypass antitrust restrictions if the merging parties can demonstrate that the merger is necessary to achieve substantial efficiencies that will enhance consumers' welfare. DeYoung (1991) shows that the Williamsonian efficiency defense was implemented by the Federal Reserve Board of Governors in deciding over bank mergers even though the U.S. Supreme Court had not recognized offsetting efficiencies as a defense of an anticompetitive merger. ${ }^{4}$

Conventional wisdom says that as firms get bigger economies of scale tend to shrink towards zeroultimately reaching to a point where the efficient scale size is achieved. Thus, regulating their size could be unnecessary. However, if banks enjoy scale economies, regulators and policymakers have to balance the benefits with the costs of further bank growth. Lower average costs may allow banks to offer more competitive prices on their services, benefiting consumers and society as a whole. On the other hand, large scale banks may increase systemic risk and crisis costs. Thus, determining if scale economies exist for banks have important implications for bank regulation (Feldman, 2010).

The literature on the existence of scale economies for U.S. banks is inconclusive. Early studies find scale economies for small banks only. According to Berger and Humphrey (1994), the conclusion that scale economies were available only to smaller U.S. banks was unshaken at the time. In contrast, more recent studies find scale economies even for the biggest financial institutions (e.g. Wheelock and Wilson 2012; Hughes and Mester 2013; Malikov, Restrepo-Tobón, and Kumbhakar 2014). However, other studies find no evidence consistent with either scale economies or increasing returns to scale (RTS) for large U.S. commercial banks (e.g. Feng and Zhang, 2012; Restrepo-Tobón and Kumbhakar, 2014; Davies and Tracey, 2014). Thus, the existence of scale economies for the biggest U.S. commercial banks is still a matter of debate.

We contribute to this literature by measuring scale economies using a novel nonparametric approach that avoids making restrictive assumptions regarding the functional form of the underlying

1 See Johnson (2012) and the references therein.

2 See for instance Davies and Tracey (2014), Glass and Stefanova (2012), Camacho and Menezes (2009), Nauges and Van Den Berg (2008), Kumbhakar and Wang (2007), Evans and Guthrie (2006), Fraquelli, Piacenza, and Vannoni (2005), Foreman and Beauvais (1999), Ellig and Giberson (1993), and Evanoff, Israilevich, and Merris (1990).

3 See Williamson 1968, Berger and Humphrey 1992, Farrell and Shapiro 2001, Schmalensee 2004, McAfee, Mialon, and Williams 2004, Lagerlof and Heidhues 2005.

4 See Kolasky and Dick (2003) and Kinne (1998) for extensive analyses of how the efficiency defense evolved in the U.S. Merger Guidelines and Laws and some merger examples in which scale economies considerations were taken into account. 
technology for banks (see Wheelock and Wilson 2011, 2012). Our approach offers two important advantages over the nonparametric methods used in previous studies. First, it gives fully nonparametric estimates of scale economies and total factor productivity (TFP) growth and its components. Previous nonparametric studies did not examine the relation between scale economies and TFP growth and did not allow estimation of other important features of the underlying technology like output-cost elasticities, technical change (TC), input price-cost elasticities, etc., making it difficult to check the consistency of their results with economic theory. Second, unlike previous studies, our method allows us to partially control for unobserved heterogeneity across banks. ${ }^{5}$ Our empirical findings indicate that failing to control for unobserved heterogeneity may conceal evidence of scale economies.

Overall, our findings suggest that most U.S. commercial banks with assets in excess of $\$ 1$ billion enjoy substantial economies of scale (Obelix is not obese). ${ }^{6}$ However, $35 \%$ of the observations for the top one hundred banks show no evidence of scale economies. ${ }^{7}$ For the top ten banks with assets ranging from $\$ 47$ billion to $\$ 1.5$ trillion, only $70 \%$ of the observations are consistent with economies of scale. ${ }^{8}$ In particular, of the four banks with assets above $\$ 500$ billion, on average, only one bank exhibits economies of scale during the sampling period (only 3 obese Obelix). Thus, capping the size of the biggest banks (converting them to Asterix) may yield limited social losses from the scale economies viewpoint.

The rest of the paper is organized as follows. In Section 2, we review the literature. In Section 3, we describe our model, the estimation strategy, and our data. In Section 4, we present our empirical results and compare them with those in the existing literature. Policy implications of our study are discussed in Section 6. Finally, Section 7 concludes.

\section{Related Literature}

During the early stages of deregulation of the U.S. banking industry, regulators and policymakers were concerned that a handful of big diversified banks could emerge and dominate the industry. Banks appeared to be able to profit from being bigger, threatening the viability of smaller specialized banks

\footnotetext{
5 We model the unobserved heterogeneity across banks as an additive fixed-effect term. This is the standard approach to control for unobserved heterogeneity in parametric models (see Chamberlain 1984, Arellano and Honore 2001, and Bai 2009). Ignoring additive unobserved heterogeneity might lead to bias and inconsistency (see Mester 1997, Greene 2005a, Greene 2005b, Kumbhakar, Lien, Flaten, and Tveters 2008, and Wang and Ho 2010). However, input prices and outputs can vary systematically as a function of input characteristics and bank business models, which may vary across banks. So input prices and outputs can have different meanings across different banks, and not all of this variation will necessarily be captured in the bank fixed effects. Further, unobserved heterogeneity can also be due to differences in costly risk-taking across banks. Note that in addition to controlling for additive fixed bank-specific effects, in our preferred model, we allow the "core" technology to be nonparametric which allows full flexibility regarding the marginal effects of input prices and outputs. Since these effects are both bank and yearspecific, differences in input prices and outputs among banks are fully captured by the nonparametric specification of the technology. In addition, we control for output quality (through nonperfoming loans), risk (via equity), and nontraditional activities (via noninterest income) to capture heterogeneity across banks that may be confounded with differing relative costs (e.g. Mester 1996, Rogers 1998) or masquerade sources of risk (e.g. Hughes and Mester 1998).

6 Following the literature, we classify big banks as those with assets above $\$ 1$ billion dollars; medium banks as those with assets greater than $\$ 100$ million and lower than $\$ 1$ billion dollars; and small banks as those with assets below $\$ 100$ million dollars. For each year, we also rank banks by assets and select the top 100 biggest banks. As of December 31, 2010; there were 479 big banks; 3,637 medium banks; and 2,290 small banks operating in the U.S. By comparison, as of December 31, 2000, there were 285 big banks; 2,397 medium banks; and 5,452 small banks. All nominal variables are in 2005 dollars.

7 The banks belonging to the top one hundred banks have assets ranging from $\$ 23$ to $\$ 1.5$ trillion.

8 The top ten biggest banks for each year are: State Street Bank and Trust Company, CitiBank, US Bank, Wachovia, HSBC, Wells Fargo, Bank of America, Bank of New York Mellon, Fleet National Bank, Suntrust Bank, Keybank, PNC Bank, Regions Bank, JP Morgan Chase, and Citizens Bank.
} 
(Clark 1988). More recently, empirical evidence shows that advances in technology and changes in regulation favor large depository institutions (Wheelock and Wilson 2011). Economists think that economies of scale may explain such phenomena. However, the empirical evidence seems, at best, inconclusive.

Before 1970, empirical studies showed evidence of scale economies among commercial banks of all sizes (see Shaffer 1994 and the references therein). During the 1970's and 1980's the bulk of empirical evidence, in contrast, showed scale economies for only small depository institutions. ${ }^{9}$ In the 1990 's, the evidence was mixed: some studies find evidence of scale economies for small banks only ${ }^{10}$ while others present evidence of scale economies even for the largest banks. ${ }^{11}$ More recent studies show evidence of scale economies across the entire bank size distribution. These studies include Wheelock and Wilson (2011, 2012), Hughes and Mester (2013), and Feng and Serletis (2010). However, Feng and Zhang (2012) find no evidence consistent with economies of scale for large U.S. commercial banks; Restrepo-Tobón and Kumbhakar (2014) find no evidence of significant economies of scale for large U.S. banks and bank holding companies; and Davies and Tracey (2014), after controlling for Too-big-to-fail factors, find no evidence of scale economies for a sample of large U.S. banks.

Wheelock and Wilson $(2011,2012)$ investigate scale economies of U.S. credit unions, commercial banks, and bank holding companies. Despite the continuous growth of these institutions since the 1980 's, they uncovered substantial economies of scale even for the largest institutions. Using yearly data from 1989-2006, Wheelock and Wilson (2011) find evidence consistent with economies of scale for all U.S. credit unions and conclude that further consolidation of the industry and increasing average size are likely. Regarding commercial banks and bank holding companies, Wheelock and Wilson (2012) find similar results. Using quarterly data from 1984-2006, their estimates support the existence of economies of scale for $99.7 \%$ of the observations. These results contrast with their earlier work, viz., Wheelock and Wilson (2001), which shows that economies of scale were exhausted when banks have assets between $\$ 300$ and $\$ 500$ million. They attribute their contrasting results to the use of a larger sample and a more realistic model of bank costs in their latest work in which equity capital and off-balance sheet activities are explicitly incorporated.

Hughes and Mester (2013) present evidence of economies of scale for large U.S. bank holding companies. They use parametric methods to estimate a model accounting for managerial risk preferences and the endogenous risk taking behavior of banks. Large banks may have lower marginal costs in risk management due to diversification. This, in turn, may lead banks to take on more risk until all the scale-related cost savings are exhausted. Thus, failing to account for managerial preferences for risk and endogenous risk taking leads to bias measures of economies of scale. ${ }^{12}$

Hughes and Mester (2013) use four different model specifications. The first model omits equity capital as a conditioning variable and also omits the cost of equity in the cost function. Using this model, they find little economies of scale for all bank holding companies in the sample. Using a second model, in which equity capital enters as a conditioning variable, they find diseconomies of scale for all bank holding companies. Results from a third model incorporating the shadow cost of equity shows evidence of slight economies of scale for all bank holding companies. However, the estimates of economies of scale are statistically indistinguishable from those of the first model. Finally, using a fourth model incorporating managerial preferences and conditioning on the optimal level of equity capital, they find substantial scale economies for all bank holding companies. In this case, estimates of economies of scale range from 1.13 for the smallest bank holding companies to 1.37 for

\footnotetext{
9 See Clark (1988), Berger, Hanweck, and Humphrey (1987), and Shaffer (1994).

10 See Berger and Humphrey (1994), Berger et al (1987), Hunter and Timme (1991), Mester (1994), Clark (1996), Hughes and Mester (1998), and Wheelock and Wilson (2001).

11 See Shaffer (1994), Hughes, Lang, Mester, and Moon (1996, 2000), Berger and Mester (1997), Hughes and Mester (1998), Berger, Demsetz, and Strahan (1999), and Hughes, Mester, and Moon (2001).

12 See also Hughes et al (1996), Hughes and Mester (1998), Hughes et al (2001), and Hughes and Mester (2010).
} 
the largest. Contrary to standard economic theory, however, their economies of scale estimates increase monotonically with bank holding companies' size. This result is puzzling since most empirical evidence, including Wheelock and Wilson $(2011,2012)$, show that economies of scale estimates decrease as bank size increases.

Feng and Serletis (2010) find evidence of increasing returns to scale (RTS) for large banks. Unlike Wheelock and Wilson (2011, 2012) and Hughes and Mester (2013) who use a cost function, Feng and Serletis use a fully parametric output distance function which does not require data on input prices. They use data for U.S. banks with assets in excess of $\$ 1$ billion from 2001 to 2005 . The main contribution of their paper is methodological in nature. They impose monotonicity and curvature constraints on the underlying bank production technology using Bayesian techniques. They claim that without such constraints, estimates of RTS and TFP growth are distorted. They obtain RTS estimates ranging from 1.037 to 1.056, indicating moderate increasing RTS for all banks in the sample. Nonetheless, from their paper, it is not clear if these results are entirely driven by their method, since they omit a comparison with the alleged misspecified model. Furthermore, in almost all banking studies, outputs are treated as exogenous and inputs as endogenous. If this is the case, one should use an input distance function in which outputs and input ratios appearing as regressors are exogenous (Das and Kumbhakar 2012). The use of output distance function suffers from endogeneity problem when inputs are endogenous.

Malikov et al (2014) estimate banks' production technology based on the ex-ante cost function. They model credit uncertainty explicitly by recognizing that bank managers minimize costs subject to given expected outputs and credit risk. They find that virtually all U.S. commercial banks (regardless of the size) operate with economies of scale. They also show that failing to control for unobserved heterogeneity across banks may conceal evidence of economies of scale and that methods estimating the ex-post realization of banking technology lead to downward biases in economies of scale estimates.

Taken together, these studies provide evidence of economies of scale for most banks. However, in a recent paper, Feng and Zhang (2012) failed to reject constant or decreasing RTS for large and small banks. They use an output distance function to model banks' technology and Bayesian techniques for estimation. Further, they impose monotonicity and curvature conditions to the underlying technology. They include continuously operating large banks (assets above $\$ 1$ billion), large community banks (assets below $\$ 1$ billion and above $\$ 100$ million), and small community banks (assets below $\$ 100$ million) from 1997 to 2006. The main distinction with Feng and Serletis is that Feng and Zhang explicitly account for technical inefficiency and random unobserved heterogeneity across banks in their estimation. Their results suggest that failing to do so leads to higher RTS estimates. In particular, without accounting for unobserved heterogeneity, large banks exhibit increasing RTS ranging from 1.022 in 1997 to 1.01 in 2006 . However, when unobserved heterogeneity is incorporated these results disappear: all large banks now exhibit constant RTS.

More recently, Restrepo-Tobón and Kumbhakar (2014) find no evidence of significant increasing RTS for large U.S. banks and bank holding companies. They use a nonparametric approach based on input distance functions which need no information on input prices, partially controlling for Too-bigto-fail cost advantages embedded in input prices. Their results show that although some big banks are operating under increasing RTS, RTS are close to unity. Davies and Tracey (2014), using a parametric approach and explicitly controlling for too-big-to-fail factors, also find no evidence of scale economies for a sample of large U.S. banks. Therefore, the literature is still inconclusive regarding the existence of economies of scale for the biggest banking organizations in the U.S.

One important criticism that may be leveled against Feng and Zhang's results is that they do not include any proxies for risk taking behavior as it is done in Hughes and Mester (2013) and Wheelock and Wilson $(2011,2012)$. Nonetheless, the fact that these latter studies do not account for unobserved heterogeneity across banks also raise questions about their reliability in line with Feng and Zhang's claims. Thus, the literature will benefit from a further investigation on these issues 
using a methodology that may combine the insights of these three lines of research: i) controlling for unobserved heterogeneity across banks, ii) conditioning on bank risk taking behavior, and iii) using flexible functional specifications for the underlying technology. ${ }^{13}$ Our paper goes one step forward in this direction. ${ }^{14}$

Another way to rationalize the observed increasing size of banks is to look at the distribution of TFP components across different bank size categories. If TFP growth differs across the bank size distribution, some banks will have incentives to increase their scale of operations, even though, by itself, this strategy may have negligible or negative impact on their performance. For instance, Hunter and Timme $(1986,1991)$ investigate how technical change interacts with bank size and scale economies. Using data for U.S. bank holding companies from1972 to 1982, they find that technical change is associated with increase in scale economies: technological change lowers cost by $1 \%$ per year, increases the cost-minimizing scale of operations, and affects banks' product mix.

Early studies indicate that TFP growth in the U.S. banking during the 1980's was modest or slightly negative (Humphrey 1991, 1992, 1993, Bauer, Berger, and Humphrey 1993, Wheelock and Wilson 1999, Stiroh 2000, Semenick Alam 2001, Berger and Mester 2003, Daniels and Tirtiroglu 1998). Tirtiroglu, Daniels, and Tirtirogu (2005) investigate how the regulatory structure of the time might have contributed to this phenomenon. They find that deregulation had a positive impact on banks' long-run productivity growth, confirming the belief that the poor productivity growth was due to regulatory restrictions. More recently, however, Mukherjee, Ray, and Miller (2001) and Semenick Alam (2001) find positive productivity growth for large U.S. banks over roughly the same period, indicating that larger banks may have taken better advantage of technological progress and deregulation.

During the period 1997-2006, Feng and Zhang (2012) find positive productivity growth for large banks, $2.04 \%$ per year on average, but poor productivity growth for small banks, $0.3 \%$ per year on average. They also show that most productivity growth gains are due to technical change and not to efficiency gains. ${ }^{15}$ These results echo those of Feng and Serletis (2010) who show that technical change contributed to $70 \%$ of total productivity growth and scale economies account for only $7 \% .{ }^{16}$

\section{Methodology}

We avoid the problem of specifying a priori any functional form for the underlying cost function. Unlike previous studies, our method exploits the dynamics between total cost and its determinants over time. We start from a purely nonparametric specification of the cost function for banks and then derive a growth equation for costs whose coefficients are nonparametric functions of the arguments of the cost function, viz., outputs, input prices, and other environmental/control variables. Similarly to Kumbhakar and Sun (2012), we use the semiparametric smooth coefficient (SPSC) model of Li, Huang, $\mathrm{Li}$, and Fu (2002) and $\mathrm{Li}$ and Racine (2010) to estimate the functional coefficients. The SPSC model arises naturally from the cost function framework and is not imposed a priori. Moreover, the functional coefficients of the SPSC model are nonparametric functions of the covariates of the cost function and are related to TFP growth and its components, including economies of scale.

\footnotetext{
13 The international evidence also points toward the existence of scale economies only for small and medium-sized banks, Amel, Barnes, Panetta, and Salleo (2004). Allen and Liu (2007), on the other hand, report economies of scale for the six largest Canadian banks.

14 Restrepo and Kumbhakar (2013) using data for all U.S. commercial banks from 2001 to 2010 also document constant RTS for most U.S. banks from 2001-2010.

15 The results for large banks are comparable to those in Feng and Serletis (2010)

16 See Hughes et al (2001) and Hughes and Mester (2010) on the impact of using different models on estimates of TFP components (e.g. scale economies, efficiency, technical change, etc.).
} 


\subsection{The Model}

We use a nonparametric cost function with $Q$ outputs, $K$ inputs, and $P$ environmental/control variables to account for some bank-specific characteristics. The cost function for bank $i$ at time $t$ has the following general specification:

$$
C_{i t}=A_{i t} \cdot B_{i} \cdot H\left(W_{i t}, Y_{i t}, t, Z_{i t}\right)
$$

where $C_{i t}$ represents actual cost, $A_{i t}$ is a productivity parameter, $B_{i}$ is a parameter capturing timeinvariant unobserved heterogeneity across banks (fixed-effects), $H(\cdot)$ is a nonparametric function of $W_{i t}$, a vector of input prices, $Y_{i t}$, a vector of output quantities, and $Z_{i t}$, a vector of control variables.

We impose homogeneity restrictions on input prices by dividing costs and input prices by the price of input $K$, i.e., $W_{K}$. Thus, the cost function becomes:

$$
\widetilde{C}_{i t}=A_{i t} \cdot B_{i} \cdot H\left(\widetilde{W}_{i t}, Y_{i t}, t, Z_{i t}\right)
$$

where $\widetilde{W}_{k}=W_{k} / W_{K}$ and $\widetilde{C}_{i t}=C / W_{K}$. Taking logarithm to $(2)$ and denoting $\ln H(\cdot)=f(\cdot)$, we can write:

$$
\ln \widetilde{C}_{i t}=f\left(\widetilde{W}_{i t}, Y_{i t}, t, Z_{i t}\right)+\ln A_{i t}+\ln B_{i}
$$

Dropping the subscripts and taking the total derivative of (3), we get the following growth formulation:

$$
\frac{d \ln \widetilde{C}}{d t}=\frac{\partial f}{\partial t}+\sum_{k=1}^{K-1} \frac{\partial f}{\partial \ln \widetilde{W}_{k}} \cdot \frac{d \ln \widetilde{W}_{k}}{d t}+\sum_{q=1}^{Q} \frac{\partial f}{\partial \ln Y_{q}} \cdot \frac{d \ln Y_{q}}{d t}+\sum_{p=1}^{P} \frac{\partial f}{\partial Z_{p}} \cdot \frac{d Z_{p}}{d t}+\frac{\partial \ln A}{\partial t}
$$

We write (4) in a more compact way to get our estimating growth equation:

$$
\dot{\widetilde{C}}=\beta_{0}(\cdot)+\sum_{k=1}^{K-1} \beta_{k}(\cdot) \dot{\tilde{W}}_{k}+\sum_{q=1}^{Q} \gamma_{q}(\cdot) \dot{Y}_{q}+\sum_{p=1}^{P} \varphi_{p}(\cdot) \nabla_{t} Z_{p}+u
$$

where, in generic terms, $\dot{X}=d \ln X / d t$ and $\nabla_{t} X=d X / d t$. We interpret $u=\partial \ln A / \partial t$ as an error term capturing productivity shocks and establish the following mapping for the functional coefficients:

$$
\beta_{0}(\cdot)=\frac{\partial f}{\partial t} ; \quad \beta_{k}(\cdot)=\frac{\partial f}{\partial \ln \widetilde{W}_{k}} ; \quad \gamma_{q}(\cdot)=\frac{\partial f}{\partial \ln Y_{q}} ; \quad \varphi_{p}(\cdot)=\frac{\partial f}{\partial Z_{p}}
$$

Note that all the functional coefficients in (5) (i.e., $\beta_{0}(\cdot), \beta_{k}(\cdot), \gamma_{q}(\cdot)$, and $\varphi_{p}(\cdot)$ ) are functions of $\widetilde{W}_{i t}, Y_{i t}, t, Z_{i t}$. Further, the unobserved time-invariant heterogeneity across banks, represented by the fixed-effects parameters $\ln B_{i}$ in (4), are removed in the growth formulation of the cost function in (5). Finally, the functional coefficients have clear economic meaning. This is shown by relating them to TFP growth and its components in the next subsection.

\subsection{Total Factor Productivity Change}

We start with the standard definition of TFP change (see Denny, Fuss, and Waverman 1979):

$$
T \dot{F} P \equiv \sum_{q=1}^{Q} R_{q} \dot{Y}_{q}-\sum_{k=1}^{K} S_{k} \dot{X}_{k}
$$


where $R_{q}$ denotes the revenue share of each output $(q=1, \ldots, Q)$ and $S_{k}$ the cost share of each input $(k=1, \ldots, K)$. In Appendix A we show that TFP growth can be expresed as:

$$
T \dot{F} P \equiv-\beta_{0}(\cdot)+\sum_{q=1}^{Q}\left(R_{q}-\gamma_{q}(\cdot)\right) \dot{Y}_{q}+\sum_{k=1}^{K-1}\left(S_{k}-\beta_{k}(\cdot)\right) \dot{\widetilde{W}}_{k}-\sum_{p=1}^{P} \varphi_{p}(\cdot) \nabla_{t} Z_{p}-u
$$

The first term is the TFP growth's technical change component $\left(T C=-\partial \hat{f} / \partial t=-\hat{\beta}_{0}(\cdot)\right)$ which captures shifts of the estimated cost function over time (percentage change in cost over time, ceteris paribus). $T C<0$ indicates technical progress (cost diminution). A positive value of TC will indicate technical regress. The second term $\left(S C=\sum_{q=1}^{Q}\left(R_{q}-\gamma_{q}(\cdot)\right) \dot{Y}_{q}\right)$ can be decomposed into two components by expressing it as $(R T S-1) \sum_{q=1}^{Q} \gamma_{q}(\cdot) \dot{Y}_{q}+\sum_{q=1}^{Q}\left(R_{q}-\gamma_{q}(\cdot) / \Gamma(\cdot)\right) \dot{Y}_{q}$ where $\Gamma(\cdot)=\sum_{q} \gamma_{q}(\cdot)$, and $R T S=[\Gamma(\cdot)]^{-1}$. The first part of it clearly depends on RTS and the second part depends on mark-up (departure of output prices from their respective marginal costs).

The third term $\left(A L=\sum_{k=1}^{K-1}\left(S_{k}-\beta_{k}(\cdot)\right) \dot{\widetilde{W}}_{k}\right)$ corresponds to the allocative component because it captures the effects of non-optimal input allocation (deviation of input mix from the optimal). The fourth term $\left(E X=-\sum_{p=1}^{P} \varphi_{p}(\cdot) \nabla_{t} Z_{p}\right)$ captures the effect of other factors such as output quality, risk, and other variables. Finally, the last term $(-u)$ is viewed as a productivity shock component which can increase/decrease TFP growth. We assume it to be random with mean zero, and can be measured residually. Note that the TFP growth components are nonparametric functions that can be computed after estimating (5).

\subsection{Econometric Model}

We estimate the functional coefficients in (5) using three different models. First, note that $f(\cdot)$ in $(5)$ can be thought of as an unknown smooth function of $t, \ln \widetilde{W}_{k}, \ln Y_{q}$, and $Z_{p}$, then its gradients, i.e., $\beta_{0}, \beta_{k}, \forall k=1, \ldots, K-1, \gamma_{q}, \forall q=1, \ldots, Q$, and $\varphi_{p}, \forall p=1, \ldots, P$, are also unknown smooth functions of these variables as shown in (6). Thus, (5) can be viewed as the SPSC model of Li et al (2002) where the model is linear in the $\dot{\widetilde{W}}_{k}, \forall k=1, \ldots, K-1, \dot{Y}_{q}, \forall q=1, \ldots, Q$, and $\nabla_{t} Z_{p}, \forall p=1, \ldots, P$, variables. To simplify notation, we rewrite (5) (after adding the subscript $i$ and $t$ for observation in the cross-sectional and time dimension, respectively) as

$$
\mathcal{Y}_{i t}=\mathcal{X}_{i t}^{\prime} \Psi\left(\mathcal{Z}_{i t}\right)+u_{i t}
$$

where $\mathcal{Y}_{i t}=\dot{\widetilde{C}}_{i t} ; \mathcal{X}_{i t}^{\prime}=\left[1, \dot{\widetilde{W}}_{1 i t}, \ldots, \dot{\widetilde{W}}_{K-1}{ }_{i t}, \dot{Y}_{1 i t}, \ldots, \dot{Y}_{Q i t}, \nabla_{t} Z_{1 i t}, \ldots, \nabla_{t} Z_{P i t}\right]$, $\mathcal{Z}_{i t}^{\prime}=\left[\ln \widetilde{W}_{1 i t}, \ldots, \ln \widetilde{W}_{K-1 i t}, \ln Y_{1 i t}, \ldots, \ln Y_{Q i t}, t_{i t}, Z_{1 i t}, \ldots, Z_{P i t}\right] ;$ and $\Psi^{\prime}(\cdot)=\left[\beta_{0}(\cdot), \beta_{1}(\cdot), \ldots, \beta_{K-1}(\cdot), \gamma_{1}(\cdot), \ldots, \gamma_{Q}(\cdot), \varphi_{1}(\cdot), \ldots, \varphi_{P}(\cdot)\right]$. We call this model the semiparametric growth model (SPG model). Appendix B shows the details of its estimation.

Second, we estimate (5) assuming that the underlying technology can be represented by a translog cost function. In this case, the functional coefficients in (5) are parametric functions of $\left[W_{i t}, Y_{i t}, t, Z_{i t}\right]$ that can be estimated by OLS (see equation (A-13) in Appendix B). We call this model the parametric growth model (PG model). ${ }^{17}$

Third, to make our results comparable to the previous literature, we estimate the cost function (1) instead of (5) assuming that the underlying technology can be represented by a translog cost function.

\footnotetext{
17 Using both the SPG and PG models, we avoid the incidental parameter problem. Consistency of the functional coefficients follow from the standard SPSC model ( $\mathrm{Li}$ et al 2002) and the standard linear panel data models as the number of observations grow to infinity.
} 
However, unlike the PG model, equation (1) does not control for unobserved time-invariant heterogeneity across banks, see Appendix B. After estimating the coefficients, we compute the functional coefficients in (5). We call this model the parametric log model (PL model).

The three models described above (SPG model, PG model, and PL model) differ in terms of their assumptions about the data generating process and the functional form of the underlying technology. Contrary to the PL model, both the SPG and PG models control for time-invariant unobserved heterogeneity across banks. Unlike the SPG model, the PG model assumes a parametric and common technology across banks. The functional coefficients of the SPG model are fully nonparametric while the PG and PL models' functional coefficients are parametric functions. In this sense the SPG model is the most general among the three.

\subsection{Data}

We focus on the post-deregulation period of the U.S. banking industry to isolate economies of scale estimates from previous regulatory restrictions that may have blocked banks ability to grow. We include the recent financial crisis to investigate how economies of scale of the biggest U.S. banks were affected during this period. Our sample covers 60,868 bank-year observations for 7,473 commercial banks from 2001 to 2010. We exclude Bank Holding Companies (BHC) which, given their idiosyncrasies, may not be comparable with most U.S. commercial banks. However, as a robustness check, we conduct a separate study regarding these institutions. Also, although quarterly data are available for balancesheet figures, we do not believe that each quarterly observation reflects banks' economic behavior over the year. Hence, we take quarterly averages of balance-sheet figures to compute yearly observations. ${ }^{18}$ Our approach incorporates a large sample of banks, a nonparametric specification of the cost function, fully flexible interactions among the explanatory variables, and includes off-balance sheet activities, nonperforming loans, and equity capital as additional control variables. ${ }^{19}$

We use data from the Report of Conditions and Income (Call Reports) from the Federal Reserve Bank of Chicago. We include all FDIC insured commercial banks with available data between 2001Q1 and 2010Q4. We exclude banks reporting negative values for assets, equity, outputs and prices, stand alone internet banks, commercial banks conducting primarily credit card activities, and banks chartered outside continental U.S. territory. Our data set is an unbalanced panel with 63,120 bank-year observations for 8,483 banks. We deflate all nominal quantities using the 2005 Consumer Price Index for all urban consumption published by the Bureau of Labor Statistics.

\footnotetext{
18 We use quarterly averages for balance-sheet figures only since end-of-year balance-sheet figures may differ from the average balance-sheet amounts a bank maintains over the year. For instance, if during the first three quarters a bank has $\$ 1$ Billion in outstanding loans but this amount is reduced significantly in the fourth quarter to $\$ 800$ million, the end-of-year amount will underestimate the total amount of loans that contributed to generate the reported interest income. In the case of balance-sheet figures used to estimate input prices, using end-of-year as opposed to quarterly averages, will lead to over-estimate them. To clarify, the approach used is to sum up the end-of-quarter figures within a specific year and divide the result by 4 . We do not do this for income statement figures since end-of-year numbers are the figures we need.

19 Risk complicates the analysis of a bank's production technology. Differences across banks regarding risk most likely lead to differences in variable cost. Without accounting for risk the assumption of cost minimization may be inappropriate. We try to account for risk taking by including some control variables like equity capital, nonperforming loans, and off-balance sheet activities which are likely to be informative regarding banks' risk taking. This is the standard approach in the literature. A more desirable approach would be to account for endogenous risk taking as in Hughes and Mester (2013) and Malikov et al (2014). Nonetheless, doing so will highly complicate our nonparametric estimation strategy. The results on Hughes and Mester (2013) and Malikov et al (2014) suggests that RTS estimates are downward bias when risk taking is not taking into account. So, we believe our results can be seen as a lower bound for economies of scale estimates.
} 
Our method is computationally demanding. To avoid extreme outliers, we use data for which output quantities and input prices fall between $0.5 \%$ and the $99.5 \%$ of their empirical distributions. In addition, we only consider banks with at least four years of available data from 2001 to 2010 . To get annual values, we compute the quarterly average of balance-sheet nominal (stock) values. As a result, we have 60,868 bank-year observations for 7,473 different banks. Our growth formulation further decreases the number of observation to 51,966 bank-year observations for 7,381 banks. However, this growth formulation removes the bank-specific fixed-effects, and therefore it does not impose any extra cost in reducing degrees of freedom.

To estimate our model, we must map banks' activities to outputs and input quantities and their corresponding prices. We follow the literature and model bank activities using the balance-sheet approach of Sealey and Lindley (1977). In this framework, a bank's balance-sheet captures the essential structure of banks' core business: (i) liabilities, together with physical capital and labor, are inputs into the bank production process and (ii) assets, other than physical assets, are outputs. Liabilities are composed of core deposits and purchased funds. Assets include loans and trading securities. Therefore, banks use labor, physical capital, and debt to produce loans, invest in financial assets, and facilitate other financial services.

We define five output variables: household and individual loans $\left(Y_{1}\right)$, real estate loans $\left(Y_{2}\right)$, business loans $\left(Y_{3}\right)$, securities (e.g., federal funds sold and securities purchased under agreements to resell) $\left(Y_{4}\right)$, and other assets $\left(Y_{5}\right)$. These outputs are essentially the same as those used in Berger and Mester (2003).

We define five input variables: labor (e.g., number of full-time equivalent employees at the end of each quarter) $\left(X_{1}\right)$, physical capital (e.g. premises and fixed assets including capitalized leases) $\left(X_{2}\right)$, purchased funds (e.g., time deposits of $\$ 100,000$ or more, federal funds purchased and securities sold under agreements to repurchase, total trading liabilities, other borrowed money, and subordinated notes and debentures) $\left(X_{3}\right)$, interest-bearing transaction accounts $\left(X_{4}\right)$, and core deposits other than interest-bearing transaction accounts or time deposits of $\$ 100,000$ or more $\left(X_{5}\right)$. The price of each input, $W_{j}$ for $j=1, \ldots, 5$, is computed by dividing total expenses by the corresponding input quantity. ${ }^{20}$ Total costs, $C$, equals the sum of expenses on each of the five inputs. Total revenue equals the sum of revenues for each output category. Table 1 presents summary statistics for outputs, inputs, and input prices.

\section{[ Table 1 approximately here ]}

Table 1 also presents information on cost, revenue, and output shares. On the revenue side, real estate loans account for $41.6 \%$ of total banks' revenues $\left(R_{2}\right)$, loan to business and other institutions $20.5 \%\left(R_{3}\right)$, securities $15.3 \%\left(R_{4}\right)$, and other assets $16.1 \%\left(R_{5}\right)$. Loans to individuals and households account for $6 \%\left(R_{1}\right)$ of total revenue. On the cost side, labor input accounts for $41.3 \%$ of total costs $\left(S_{1}\right)$, non-transaction accounts expenditures represent $29.2 \%\left(S_{5}\right)$, premises and fixed assets $10.3 \%$ $\left(S_{2}\right)$, purchased funds $16.6 \%\left(S_{3}\right)$, and transaction accounts $2.6 \%\left(S_{4}\right)$. In addition, Table 1 also reports output shares for each output category, $S Y_{i}$; and the share of total loans on total output, $S Y_{123}$. In addition, we include the log of total equity capital $\left(Z_{1}\right)$ as a a quasi-fixed netput, a proxy for offbalance sheet activities $\left(Z_{2}\right.$ : noninterest income over total income), and a proxy for output quality $\left(Z_{3}\right.$ : non performing loans).

\footnotetext{
20 We treat physical capital as a variable input and compute its price for each year as the ratio between expenses of premises and fixed assets over the quarterly average of total premises and fixed assets. Ideally, one should use the opportunity cost of such assets for this computation. We believe, however, that since expenses of premises and fixed assets include all non-interest expenses related to the use of premises and fixed assets, including capitalized leases, net of their rental income, our approach may reasonably resemble the opportunity cost of using such assets.
} 


\section{Empirical Results}

Both the SPG model and the PG models fit the data quite well (the $R^{2}$ values for these models are $0.978,0.916) .{ }^{21}$ The PG model is a restricted version of the SPG model. Thus, we can test if the data support the parametric restrictions imposed by the PG model. Using the specification test of Li and Racine (2010), we reject the PG model in favor of the SPG model specification. ${ }^{22}$ Thus, on statistical grounds our preferred specification is the SPG model. However, our findings regarding economies of scale and TFP growth components from the SPG and PG models are quite similar. For completeness and comparability with the literature, we present parameters, economies of scale, and TFP growth components estimates from all three models.

\subsection{Estimated Functional Coefficients}

The functional coefficients from the SPG model are fully nonparametric and have clear economic meaning. As mentioned before $\beta_{0}(\cdot)$ captures shifts of the cost function (percentage change in cost, ceteris paribus). Similarly, each $\beta_{k}(\cdot)$ represents the cost elasticity of input price $k$ - cost shares. The $\gamma_{q}(\cdot)$ coefficients capture the cost elasticity of outputs and are uniquely related to economies of scale. Finally, the $\varphi_{p}(\cdot)$ coefficients measure the effects of the control variables on the percentage change in cost. We present summary statistics for the functional coefficients estimates in Table 2 and their empirical distributions in Figure 1.

\section{[ Table 2 and Figure 1 approximately here]}

It can be seen from Table 2 that mean TC is almost zero in SPG and PL models. However looking at the mean might give a misleading impression. A closer look at TC in the PL model shows that it is almost zero for each percentile while for the SPG model there is technical progress (negative TC) for almost half of the banks while for the other half there is technical regress. These opposing forces resulted in a technical regress of $0.1 \%$ per annum. On the other hand, the PG model shows technical progress ranging from $2.1 \%$ to $0.00 \%$, for more than $75 \%$ of the banks. On average, technical progress took place at the rate of $1 \%$ per annum.

By Shephard's lemma, the coefficients $\hat{\beta}_{k}(\cdot)=\partial \ln C / \partial \ln W_{k}$, are cost shares estimates for each input, $k=1,2,3,4$. The mean and the empirical distributions of $\hat{\beta}_{k}(\cdot)$ from the SPG and PG models are similar and closely follow the observed cost shares shown in Table 2. The estimates from the PL model follow a similar pattern but their empirical distributions differ significantly. Negative values for $\hat{\beta}_{k}(\cdot), k=1,2,3,4$., indicate violations of regularity conditions since cost shares are positive. Tables 3 and 4 show that most $\hat{\beta}_{k}(\cdot)$ are positive. For the SPG model the violations are less than $0.5 \%$ for $\hat{\beta}_{1}(\cdot)$ and $\hat{\beta}_{3}(\cdot)$, and around $6 \%$ for $\hat{\beta}_{2}(\cdot)$ and $\hat{\beta}_{4}(\cdot)$. For the PG model, the violations are less than $0.5 \%$ for all $\hat{\beta}_{k}(\cdot)$. The PL model has the largest number of violations, $27 \%$ and $11.5 \%$ for $\hat{\beta}_{2}(\cdot)$ and $\hat{\beta}_{4}(\cdot)$, respectively. Our results imply that controlling for unobserved heterogeneity using the SPG or the PG models reduces the number of violations significantly.

\section{[ Tables 3 and 4 approximately here]}

Estimated cost elasticity with respect to each output is given by $\hat{\gamma}_{q}(\cdot)$. We expect these coefficients to have a positive sign since both marginal and average costs are positive. In fact, this is the case for

\footnotetext{
21 The fit of the PL model $\left(R^{2}\right)$ is not comparable to the other two models because the dependent variables are not the same. The $R^{2}$ of the PL model is 0.847 .

22 We use 99 bootstrap replications which gave a p-value of almost zero.
} 
most observations. Estimates of $\gamma_{q}(\cdot)$ from the PG model are negative for less than $0.8 \%$ of all observations. The SPG model shows negative values for $\hat{\gamma}_{2}(\cdot)$ to $\hat{\gamma}_{4}(\cdot)$ for less than $1.2 \%$ of the observations. The corresponding values for $\hat{\gamma}_{1}(\cdot)$ and $\hat{\gamma}_{5}(\cdot)$ are $5.6 \%$ and $6.25 \%$. Overall, the PL model gives negative values for $\hat{\gamma}_{k}(\cdot)$ for less than $6 \%$ of the observations. The low number of violations for the SPG model is remarkable since its estimated coefficients are fully nonparametric functions. Better performance of the PG model in this regard suggests that the PG model is a good approximation of the underlying technology. We consider that the number of sign violations for the estimated coefficients $\hat{\beta}_{k}(\cdot)$ and $\hat{\gamma}_{k}(\cdot)$ using the SPG and PG models are low. Thus, we do not restrict their signs. ${ }^{23}$

The $\hat{\varphi}_{p}(\cdot)=\partial \hat{f} / \partial Z_{p}$ coefficients capture the effects of log of equity capital $\left(Z_{1}\right)$, off-balance sheet activities $\left(Z_{2}\right)$, and non-performing loans $\left(Z_{3}\right)$ on log total cost. More specifically, $\hat{\varphi}_{1}(\cdot)$ represents cost elasticity of equity capital, while $\hat{\varphi}_{p}(\cdot), p=2,3$ represents semi cost elasticity of off-balance sheet activities and non-performing loans. For the SPG and PG models, the estimated mean effects are all positive, indicating that increases in any of these variables to produce a given level of outputs increase total cost, ceteris paribus. ${ }^{24}$

It is noteworthy that all the estimated functional coefficients are well behaved as shown by their empirical distributions (Figure 1). This is particularly remarkable for the nonparametric functional coefficients of the SPG model since they are completely unconstrained. The functional coefficients in all three models are observation-specific. Thus, we compute their standard errors using the wild bootstrap method of Hardle and Mammen (1993). Figure 2 shows the observation-specific functional coefficient estimates from the SPG model along with their $95 \%$ confidence intervals. Unreported results show a similar pattern for the PG and PL models.

\section{[ Figure 2 approximately here ]}

To understand these figures, consider the plot for the estimated functional coefficients $\hat{\beta}_{0}(\cdot)$ in Figure 2. We plot $\hat{\beta}_{0}(\cdot)$ against $\hat{\beta}_{0}(\cdot)$ such that all the coefficients $\hat{\beta}_{0}(\cdot)$ lie along the $45^{\circ}$ line. The points above (below) the $45^{\circ}$ line represent the upper (lower) bound of each confidence interval. Therefore, for each $\beta_{0}(\cdot)$ on the $45^{\circ}$ line we can see an observation-specific confidence interval. If the horizontal line at zero passes inside of the confidence bounds for any given observation, then $\beta_{0}(\cdot)$ for this observation is statistically insignificant. Conversely, if the horizontal line at zero passes outside of the confidence bounds, then $\beta_{0}(\cdot)$ for this observation is statistically significant. In addition, if the lower (upper) bound lies above (below) zero, then the coefficient for this observation is significantly positive (negative). In general, the confidence intervals for each of the functional coefficients are quite tight, although they become wider at the tails.

\subsection{Economies of Scale}

We present summary statistics for economies of scale estimates using the SPG, PG, and PL models in Panels A, B, and C of Table 5. Figures 3 and 4 show their empirical distributions. We find economically and statistically significant scale economies, as measured by RTS, for most banks. For the SPG model (Panel A), mean RTS estimate is 1.42 , indicating that if outputs were to increase by $10 \%$, total costs will increase approximately by $7 \%(10 \% \times 1 / 1.42)$. Mean RTS estimates from the PG model (Panel

\footnotetext{
23 Such an exercise is beyond the scope of the present. We leave this for future research.

24 The positive relationship between the growth in variable cost and equity capital suggests that to produce a given output vector with more equity capital banks also spend more on variable inputs. Apart from possible agency problems, two potential and important explanations could be that to do so banks spend more on either reducing or taking on more risk. If nonperforming loans are a valid proxy for realized credit risk, the positive relationship between variable cost and nonperforming loans seems to be consistent with the latter explanation. This discussion is not central to our paper and since it deserves a deeper analysis we left it for future research.
} 
B) is 1.40. These results indicate presence of increasing RTS (IRTS) for most banks. The mean RTS from the PL model (Panel C) is 1.01, indicating constant RTS (CRTS). The empirical distribution of estimated RTS from the SPG or PG models show decreasing RTS for less than $2 \%$ of the observations. In contrast, estimated RTS from the PL model show decreasing RTS (DRTS) for about $42 \%$ of the observations.

[ Table 5 approximately here]

[ Figures 3 and 4 approximately here]

Estimated RTS decrease with bank size, see Table $5 .^{25}$ Mean RTS for small, medium, and big banks are 1.56, 1.34, and 1.18 from the SPG model and 1.54, 1.32, and 1.10 from the PG model. Mean RTS for the top 100 banks are also lower than for all other banks. Estimated RTS from the SPG and PG models show that almost all medium and small banks exhibit IRTS. More than $75 \%$ of big banks and more than $50 \%$ of the top 100 banks also exhibit IRTS. Estimates RTS from the PL model show IRTS for about $50 \%$ of banks. ${ }^{26}$

The RTS estimates from the SPG and the PG model are directly comparable in the sense that both models controls for fixed bank-specific effects. This is, however, not the case with the PL model. Thus the differences in RTS estimates in the PL model from the other two models might be attributed to ignoring bank-specific effects. Estimated RTS from the PL model are both statistically and economically smaller than those from the PG model, indicating that failure to account for time-invariant unobserved heterogeneity conceals the evidence of substantial scale economies for most banks.

Now we investigate the statistical significance of our RTS estimates. In Figure 5, we depict the estimated $95 \%$ confidence intervals for RTS estimates by bank size for each model. In Table 6 , we report the percentage of observations exhibiting statistically significant increasing, decreasing, or constant RTS. For each plot in Figure 5, points above (below) the $45^{\circ}$ line represent the upper (lower) bounds of observation-specific confidence intervals. Points on the $45^{\circ}$ line are the estimated RTS. If the horizontal line at one passes inside of the confidence bounds for any given observation, then RTS estimate for this observation is statistically equal to one (CRTS). If the lower (upper) bound lies above (below) one, then the RTS estimate for this observation is significantly greater (less) than one, indicating IRTS (DRTS).

\section{[ Figure 5 approximately here]}

The confidence intervals in Figure 5 are consistent with the existence of IRTS for most banks reported above. In the SPG model, $98 \%$ of the observations for medium and small banks show presence of IRTS. The corresponding values for big and the top one hundred banks are $75 \%$ and $65 \%$, respectively (see Table 6). Only $2 \%$ of the observations for medium and small banks show presence of CRTS and none shows evidence of DRTS. Only $13 \%$ of the big banks and $26 \%$ of the top one hundred banks show evidence of DRTS.

\section{[ Table 6 approximately here ]}

The evidence from the PG model is consistent with the results from the SPG model, except for the top one hundred banks. The estimates from the PG model show evidence of IRTS for $100 \%, 74 \%$, and $23 \%$ of medium and small banks, big banks, and the top one hundred banks, respectively. In contrast, estimates from the PL model show no evidence of IRTS for most banks.

\footnotetext{
25 We classify banks by total assets as follows: Big (assets $>\$ 1$ billion), medium $(\$ 100$ million $<$ assets $<\$ 1$ billion), and small (assets $<\$ 100$ million) banks. The top 100 banks correspond to the 100 biggest banks by assets each year. This classification is typically used in the literature (see Feng and Serletis, 2009)

26 RTS estimates from the SPG model has more extreme values than those from the PG model. This is expected from a nonparametric model. That is, the distribution of RTS from the PG model is quite tight.
} 
We plot the relation between RTS estimates and bank size in Figure 6 for the SPG and PG models. RTS estimates from the SPG and PG models decrease monotonically as bank size increases. There is a clear inverse relation between RTS and bank size - measured by size deciles. The interquartile range of RTS estimates tend to be wider for the smallest and the biggest banks. Unreported results show that the empirical distribution of bank size is almost the same for the biggest one hundred banks that exhibit either increasing or decreasing RTS. Thus, for the biggest one hundred banks (as measured by total assets) RTS estimates are unrelated to bank size, suggesting that some of these banks will continue growing irrespective of their actual size.

\section{[ Figure 6 approximately here ]}

Table 7 presents additional results concerning the distribution of RTS for the biggest ten banks in our sample from 2001 to 2010. RTS estimates for these banks are lower for the crisis years (2007-2009). We investigate this issue further by estimating the SPG model using dummy variables for the crisis years and including in the sample only banks with more than $\$ 500$ million in assets (results not shown). We find that RTS estimates are also lower during the crisis years but the fall in their magnitude is not as pronounced. Thus, there seem no to be a significant change in banks' cost structure during those years.

\section{[ Table 7 approximately here]}

Based on transition probability matrices (not reported), we find that RTS estimates from the SPG model are stable over time. The likelihood of remaining within the same RTS decile or switching to the two adjacent RTS deciles are around $70 \%$ for the SPG model and $90 \%$ for the PG model, suggesting that the RTS estimates from the PG model are more stable over time. This may stem from the parametric assumptions underlying the PG model. In contrast, the SPG model RTS estimates are fully nonparametric. Nonetheless, the probabilities of switching across deciles that are farther away from each other are small for both models, indicating that there are no large swings on the estimated RTS. Unreported piece-wise Spearman rank correlations show that the rank correlation for adjacent years are high for both the SPG and the PG model (above 0.75 and 0.98 , respectively). These results are consistent with the transition probabilities matrix analysis discussed before and may stem from the fact that the parametric specification imposes stronger restrictions on the dynamics of RTS estimates in contrast to the fully nonparametric RTS estimates from the SPG model.

\subsection{TFP Growth and its Components}

We compute TFP growth (the Divisia) from $T \dot{F} P \equiv \sum_{q=1}^{Q} R_{q} \dot{Y}_{q}-\sum_{k=1}^{K} S_{k} \dot{X}_{k}$. Note that the Divisia can be computed directly from the data without estimating any econometric model. In order to decompose it into technical change, scale, allocative, control, and random components using (8), we need to estimate the components econometrically. That is, in an econometric model one estimates the components and then adds them to compute TFP growth. Table 8 summarizes the results and Figure 7 presents density estimates for TFP growth and its components. The first row of each panel in Table 8 corresponds to the estimated TFP annual growth rate. Since the SPG and PG models use a growth formulation, TFP growth rates differ from the Divisia TFP growth rate only by the random component which has a zero mean. This is why TFP growth obtained from adding the components equals the Divisia index. This is, however, not the case in the PL model in which the error term is not the same as the last component of TFP growth in (8). ${ }^{27}$

\footnotetext{
27 See Kumbhakar and Sun (2012) for a discussion on this issue based on an input distance function formulation.
} 


\section{[ Table 8 approximately here] \\ [ Figure 7 approximately here]}

Average annual TFP growth rate is $3.1 \%$ with a standard deviation of $8.3 \%$. Average TFP growth using either the SPG or the PG model equals the average Divisia TFP growth rate but its standard deviation is lower, reflecting the absence of the random component. Average TFP annual growth rate using the PL model is $1.1 \%$ with a standard deviation of $8.4 \%$. Since the the PL model uses data in logs, it fits total cost changes less accurately, resulting in a large unexplained component (which is zero on average in both the SPG and PG models). Thus, TFP growth rate estimates from the PL model is likely to differ from the Divisia TFP growth rates. ${ }^{28}$

The top left panel of Figure 8 shows estimated average annual TFP growth rate over time for the Divisia and the three econometric models. TFP growth rates are positive over the sample period for the Divisia, the SPG and PG models. TFP growth rates are higher from 2007 to 2010 than from 2002 to 2006. This pattern coincides with the U.S. financial crisis period. However, except for an increase in the elasticity of cost with respect to real estate loans, there is no apparent change in the cost structure for most banks. ${ }^{29}$ This result holds for the Divisia, the SPG and PG models. In contrast, TFP growth rate estimates using the PL model overestimate TFP growth rates from 2002 to 2006 and underestimate TFP growth from 2007 onwards. Compared with 2001 levels, the TFP indexes from the Divisia, the SPG and PG models increase about $33 \%$ by 2010 (see the top right plot in Figure 8). The PL model's TFP index shows that the increase was only about $11 \%$. SPG model's average annual TFP growth rate for big, medium, and small banks are $3.9 \%, 3.1 \%$, and $3 \%$, respectively. For the PG model, the corresponding values are $3.3 \%, 3.3 \%$, and $2.9 \%$; and for the PL model they are $1.6 \%, 1 \%$, and $1.1 \%$.

\section{[ Figure 8 approximately here]}

Taken together, these results suggest that estimating the underlying parameters of the cost function without controlling for unobserved heterogeneity may lead to biased estimates of TFP growth components. In particular, in the PL model the mean difference between the annual total cost change and its estimate is $-2 \%$. This is exactly the difference between the average TFP growth estimated from the PL model and the Divisia. Therefore, without controlling for time-invariant unobserved heterogeneity, the parameter estimates of the underlying cost function are biased. As a consequence, the PL model attributes most of the TFP growth to the random component. Now we focus on the sources of TFP growth by examining each component separately.

\subsubsection{Scale Economies}

The scale component of TFP in (8), $\sum_{q=1}^{Q}\left(R_{q}-\gamma_{q}\right) \dot{Y}_{q}$, can be rewritten as $(R T S-1) \sum_{q=1}^{Q} \gamma_{q}(\cdot) \dot{Y}_{q}+$ $\sum_{q=1}^{Q}\left(R_{q}-\gamma_{q}(\cdot) / \Gamma(\cdot)\right) \dot{Y}_{q}$ where $\Gamma(\cdot)=\sum_{q} \gamma_{q}(\cdot)$. The presence of scale economies (IRTS) contributes positively to TFP growth if output growth rates $\left(\dot{Y}_{q}\right)$, weighted by the elasticity of cost with respect to each output $\left(\gamma_{q}\right)$, are positive. If the marginal cost for each output equals the corresponding output price, then $R_{q}=\gamma_{q} / \Gamma_{q}$ which means $\sum_{q=1}^{Q}\left(R_{q}-\gamma_{q} / \Gamma_{q}\right) \dot{Y}_{q}=0$. If not, this component will be non-zero and can be interpreted as the mark-up component. The means of this mark-up component for the SPG, PG, and PL models are $0.6 \%, 0.3 \%$, and $0.2 \%$, respectively.

\footnotetext{
28 This finding is not new in the TFP growth literature. For example, see Kumbhakar and Lozano-Vivas (2005) and the references cited in there.

29 As one of the anonymous referees notice, these results could be of independent interest. We leave a throughout analysis of them for future research.
} 
The mean of the scale component estimates equals $2.2 \%, 1.8 \%$, and $0.2 \%$ for the SPG, PG, and PL models, respectively. Thus, on average, economies of scale contribute positively to TFP growth. Compared with medium and small banks, the contribution of scale economies to TFP growth is higher for big banks.

The positive contribution indicates that, on average, $R_{q}-\gamma_{q}(\cdot) \geq 0$, which means that the effects of output price changes on total revenue are higher than the corresponding effects of output quantity changes on cost (i.e., a $1 \%$ change in a given output causes a proportional change in total cost that is lower than the proportional change in total revenue caused by a $1 \%$ increase in the corresponding output price.)

The lower-left plot of Figure 8 shows that the scale component for the SPG and PG models are similar. The SPG scale component tends to grow faster, however, reflecting the higher RTS obtained using the SPG model. This plot also shows that the differences in estimated RTS between the SPG and PG model are small and their contributions to TFP growth are comparable.

Our results strongly support the hypothesis that most U.S. commercial banks enjoy substantial economies of scale. Our nonparametric RTS estimates (SPG model) indicate that, on average, more than $98 \%$ of banks experience increasing RTS. However, we reject the hypothesis of increasing RTS for $26 \%$ of the observations for the biggest U.S. banks.

\subsubsection{Technical Change}

From (8), the contribution of TC to TFP growth is $-\beta_{0}(\cdot)=-\partial \hat{f} / \partial t$. Estimates of TC from the SPG and the PG models show an annual rate of technical change about $-0.1 \%$ and $1 \%$, respectively (see Table 2). Results from these two models also show that big banks experience higher rates of TC than medium and small banks. Mean TC from the SPG model are $0.6 \%,-0.1 \%$, and $-0.1 \%$, for big, medium, and small banks, respectively. The corresponding values from the PG model are $1.7 \%, 0.9 \%$, and $1 \%$.

These differences lead to different temporal paths of TC as shown in the left-middle plot of Figure 8. Estimates of TC from the PG model show that banks experience substantial gains in TFP growth. The SPG model suggests that total cost remains essentially unchanged from 2001 to 2010, ceteris paribus. Given that the SPG model imposes fewer constraints on the model and therefore on the dynamics of TC, we take the results from this model more seriously.

\subsubsection{Allocative Component}

TFP growth is also affected by deviations of actual input cost shares, $S_{k}$, from the optimal input cost shares, $\beta_{k}$. This happens when banks fail to allocate inputs optimally. The allocative component, $A L=\sum_{k=1}^{K-1}\left(S_{k}-\beta_{k}\right){\widetilde{W_{k}}}_{k}$, captures the contribution of such input misallocations (over- or under-use of inputs) on TFP growth. If $S_{k}=\beta_{k}, k=1, \ldots, 4$, then there is no input mis-allocation and therefore $A L=0$. The sign on $A L$ depends on the extent of input mis-allocation as well as rate of change in relative inputprices.

The average contribution of AL in the SPG and PG models are $1.7 \%$ and $0.7 \%$, with standard deviation of $4.2 \%$ and $3.8 \%$. For the PL model it is $0.8 \%$ with a standard deviation of $5.7 \%$. Figure 8 shows the temporal behavior of AL in the three models. The AE component from the SPG model shows an increase of about 17\% during 2001 to 2010. The corresponding values for the PG and PL models are about $6 \%$ and $7 \%$, respectively. The AL component from the SPG model show a steady increase during the sample period. On the other hand, the PG and PL models show increases up to 2004, decreases for 2005 and 2006, and steady gains thereafter. The estimates from all three models indicate allocative efficiency gains from 2007 to 2010. 
Gains from AL predicted by the SPG model are $2 \%$ for big banks, $1.6 \%$ for medium, and $1.8 \%$ for small banks. The corresponding values from the PG model are $0.8 \%, 0.7 \%$, and $0.7 \%$, respectively. In contrast, the estimates from the PL model are about $0.8 \%$ regardless of bank size.

\subsubsection{Component attributed to environmental factors}

TFP growth can also be affected by factors other than technical change, allocative efficiency, and scale economies. We consider three such environmental factors, viz., (log) equity capital $\left(Z_{1}\right)$, non-traditional activities (off-balance sheet activities: $Z_{2}$ ), and non-performing loans $\left(Z_{3}\right)$. The contribution of these control/environmental variables to TFP growth is capture by $E X=-\sum_{p=1}^{P} \varphi_{p}(\cdot) \nabla_{t} Z_{p}$ in (8). The EX values for the SPG and PG models follow a similar pattern over time. Average values of EX from the SPG and PG models are small but negative, $-0.7 \%$ and $-0.4 \%$, with standard deviations of $2.5 \%$ and $1.2 \%$, respectively. Thus, these environmental variables contribute negatively to TFP growth. However, their effects are small compared with the other components. The last plot in Figure 8 shows that the cumulative effect of the environmental variables for the 2001 to 2010 period based on the SPG model is about $-6 \%$ and is about $-3 \%$ predicted by the PG model. On the other hand, the PL model show that the EX component contributed positively to TFP growth.

To summarize the results of the preceding section, TFP grew about 33\% during 2001 to 2010. According to the SPG model the main drivers of TFP growth were scale economies and allocative efficiency which account for $21.5 \%$ and $17.3 \%$, respectively, of TFP growth during this period.

The trend of TFP growth for big, medium, and small banks is similar. However, big banks experience sharper swings in TFP growth than medium and small banks. TFP grew steadily for all banks from 2001 to 2010 with some periods of deceleration. TFP grew $44.6 \%, 32.2 \%$, and $32.3 \%$ for big, medium, and small banks. During 2008 to 2010, TFP growth for big banks was 1.5 times higher than for medium and small banks.

Unlike previous studies, our framework allows us to tie the functional coefficients of our models to TFP growth components, allowing us to investigate the main forces explaining U.S. banking industry growth. Our results show that increasing returns to scale played an important role in explaining growth of the U.S. banking industry. By comparison, the role of technical change is smaller. These results are consistent with recent evidence presented by Diewert and Fox (2008) for the U.S. manufacturing industry.

\section{Robustness Checks}

We conduct several robustness checks to challenge our results. As pointed out by DeYoung (2010), evidence of scale economies for big banks may be driven by inclusion of very small banks in the estimation. Thus, we re-estimated the SPG model using data for commercial banks with assets in excess of $\$ 500$ million. In this case, median scale economies estimates falls to 1.16 from 1.37 (see Table 5). For banks with assets in the 90th percentile, median scale economies are slightly higher, 1.18. Thus, despite the drop in median scale economies for this subsample, there is still strong evidence of scale economies for even the biggest banks.

We also investigate whether our estimates change when controlling by the financial crisis of 20072009. We re-estimated the SPG model including data for commercial banks with assets in excess of $\$ 500$ million and included a dummy variable for the crisis years. Except for an increase in the elasticity of total costs with respect to real estate loans for the biggest banks, our results indicate no change in the cost structure of banks during the crisis years. RTS estimates in this case are slightly lower but the results are still consistent with substantial scale economies. 
Selecting/including output categories appropriately is an important issue in measuring scale economies. Off-Balance-Sheet (OBS) activities accounts for an important part of non-interest income for banks which suggests including it as an output and not as a control variable. We conducted a separate estimation for large commercial banks with assets greater than $\$ 500$ million including OBS activities (with the level of non-interest income as a proxy) as an additional output. ${ }^{30}$ Compared with the results presented previously in Table 5, OBS has a very small impact on our estimates of RTS. Without OBS as an additional output, mean RTS estimate for banks with total assets greater than $\$ 1$ billion was 1.18. Using OBS as an additional output leads to a mean RTS estimate for these banks of 1.19. In addition, about $80 \%$ of the RTS estimates are greater than 1.05, indicating that a great proportion of the biggest commercial banks enjoy significant economies of scale. In this sense, the qualitative results of the paper do not change.

In our previous specifications, we treat nonperforming loans as a control variable for risk and measure it as a ratio. However, nonperforming loans could be considered as a quasi-fixed input since to produce more output, especially loans, banks could opt to take on more credit risk. The derivative of cost with respect to the level of nonperforming loans would indicate its relationship to cost and an indication of how variable cost varies with realized credit risk. Thus, we re-estimated the model using nonperforming loans in level as a quasi-fixed input for banks with assets in excess of $\$ 500$ million. We find that the overall relation between realized credit risk and variable costs is positive, indicating that as banks take on more credit risk, variable costs also increase. The inclusion of nonperforming loans in levels does not change significantly our RTS estimates, however. In addition, we find no specific pattern on the relationship between realized credit risk and total cost as a function of bank size.

To investigate the consistency of our scale economies estimates with those recently reported in the literature, we compare them with those in Hughes and Mester (2013) and Wheelock and Wilson (2012). From their preferred model specification, Hughes and Mester (2013) report mean scale economies as high as 1.43 for the biggest U.S. Bank Holding Companies (BHCs) operating in 2010 (see page 573). In comparison, our mean scale economies estimate for the top one-hundred banks is 1.12 and for the ten biggest banks is 1.21 (see Table 7). In addition, Wheelock and Wilson (2012) find that for the 20 biggest BHCs in their sample, scale economies were about $1.25 .^{31}$ Thus, our results seems lower than those recently reported in the literature.

We use annual US Call Report data for individual commercial banks. However, several banks operate under a BHC. Hence, a BHC may conduct its subsidiary banks as part of an overall business strategy. Thus, investigating scale economies at the commercial bank level may not capture the overall BHC strategy and cannot account for the dependence between multiple institutions owned by the same BHC. Thus, our empirical results are to be interpreted in the context of commercial banks only. We re-estimated the model using data for Bank Holding Companies from 2001 to 2010. Contrary to our results for individual commercial banks, we find that most BHCs exhibit decreasing returns to scale (the results are available from the authors upon request). Median returns to scale for this sample is about 0.726. Notably, for the biggest BHCs (those belonging to the 90th decile by asset size) this estimate is about 0.77 . Hence, there are substantial differences between scale economies estimated for individual banks and those for BHCs.

\footnotetext{
30 We thank two anonymous referees for this suggestion.

31 Wheelock and Wilson (2012) do not report specific measures of scale economies. However, from their discussion on page 192 we could back up the value of 1.25 for the biggest 20 BHCs. They explain that by reducing the size of a BHC like Citibank by a factor of 0.5012 leads to a decrease in costs by a factor $1-0.5952$. This is equivalent to a decrease of $0.4008=0.5012 \times 1 / 1.2504=1-0.5952$. Equivalently, increasing the size of Citibank by $1 \%$, would increase its costs by only $0.7997 \%(1 \% \times 1 / 1.2504)$. Given the size of Citibank in 2006 (measured by assets) of $\$ 1.885$ trillion dollars, the $1 \%$ increase in total assets ( $\$ 18.85$ billion) will lead to an increase in total costs of $\$ 15.07$ billion $(\$ 18.85 \times 1 / 1.2504)$ which implies scale economies of $\$ 3.77$ billion.
} 


\section{Regulatory Implications}

Despite the wide range of problems recently addressed by enacted financial regulations in the U.S., policymakers, regulators, academics, and financial market participants are still pondering the idea of capping the size of banks, bringing the issue of existence of scale economies to the fore of the policy debate. If big banks enjoy substantial scale economies, breaking up the biggest banks or capping their size may impose efficiency losses to the economy.

Wheelock and Wilson (2012) estimate that the cost of breaking the four largest U.S. bank holding companies in existence in 2010 would hover $\$ 79$ billion annually. On the other hand, Boyd and Heitz (2012) estimates that the potential benefits to the society from economies of scale of big financial institutions are unlikely to ever exceed the potential costs due to increased risk of financial crisis. Our results have important implications for this debate.

First, our findings suggest that most of the biggest U.S. commercial banks enjoy substantial economies of scale (Obelix is not obese). However, as evidenced in Table 6, not all the banks with assets in excess of $\$ 1$ billion exhibit economies of scale. Further, the RTS estimates for $35 \%$ of the observations belonging to the top one hundred banks are consistent with constant or decreasing RTS. ${ }^{32}$ For the top ten banks with assets ranging from $\$ 47$ billion to $\$ 1.5$ trillion, only $70 \%$ of the observations produce RTS estimates consistent with increasing RTS. ${ }^{33}$ In particular, of the four banks with assets above $\$ 500$ billion, on average, only one bank exhibits increasing RTS during the sampling period (only 3 obese Obelix). Thus, capping the size of banks around $\$ 1$ trillion (converting them to Asterix), for instance, may yield limited social losses from the scale economies viewpoint.

Second, our results indicate that scale economies are likely to continue to be the major driver of growth for small, medium, and some of the biggest banks. We find that scale economies contribute significantly to TFP growth, giving strong incentives for banks to keep growing and, to regulators, a more challenging and difficult task to keep them on lean diet. If regulators want to keep bank size under control, they will have to consider ways in which banks internalize the associated potential cost for society. This will likely require imposing endogenous regulatory constraints that increase the marginal cost of getting bigger above the marginal benefits of getting even bigger.

Third, consolidation of small and medium banks and further growth of some of the biggest banks pose big challenges to regulators. As overall bank size increases, widespread bank failures can be more problematic for regulators. Future bank failures will likely involve, on average, bigger and more interconnected banks. Therefore, regulators should widen the focus of their efforts beyond the biggest commercial banks and BHCs and look in the direction of smaller banks that have the strongest incentive to keep growing. In addition, larger average size of banks means stronger barriers to entry for potential competitors which can greatly affect concentration, competition, and efficiency.

\section{Conclusions}

Regulators in the U.S. and around the world are still pondering the idea of how to keep bank size in check. Thus, understanding whether the biggest U.S. banks enjoy economies of scale is important. In this paper, we offer new nonparametric estimates of scale economies, TFP growth and its components (technical change, scale, and other environmental variables) for U.S. commercial banks during 2001 to 2010. We show that most, but not all, banks have economic incentives to keep growing since they

\footnotetext{
32 The banks belonging to the top one hundred banks have assets ranging from $\$ 23$ to $\$ 1.5$ trillion.

33 Including the years 2007 and 2008, only $57 \%$ of the observations for the top ten biggest banks are consistent with increasing RTS. Among the top ten biggest banks for each year are State Street Bank and Trust Company, CitiBank, US Bank, Wachovia, HSBC, Wells Fargo, Bank of America, Bank of New York Mellon, Fleet National Bank, Suntrust Bank, Keybank, PNC Bank, Regions Bank, JP Morgan Chase, and Citizens Bank.
} 
enjoy substantial economies of scale. Even the biggest U.S. commercial banks seem to be below their optimal size. Thus, further growth and industry consolidation are likely to continue.

Our economies of scale estimates are derived from a novel and more flexible approach than those used in the previous studies. We start from a nonparametric cost function with fixed bank-specific effects and derive an estimating equation that is a semiparametric smooth coefficient (SPSC) cost function. The smooth coefficients are nonparametric (fully flexible) functions of the covariates of the cost function and therefore the estimates of scale economies, TFP growth, and its components are nonparametric. We compare the results from the SPSC model with two other models that are parametric but flexible. These features are absent from most recent studies.

For U.S. commercial banks, we find that around $73 \%$ of the top one hundred banks, $98 \%$ of medium and small banks, and seven of the top ten biggest banks by asset size exhibit substantial economies of scale. In addition, scale economies contribute positively and significantly to their TFP growth. Thus, the existence of substantial scale economies at commercial banks raises an important challenge for regulators to pursue size limit regulations. We show that our results for commercial banks are robust to a alternative model specifications and sampling mechanisms. Our economies of scale estimates are in line with those appearing in the recent literature.

Unlike previous studies, we find that the major drivers of TFP growth are the scale and allocative components. Technical change and other factors, like changes in loan quality, risk, and off-balance sheet activities, affect TFP growth marginally. This reinforces our main conclusions that banks still have incentives to growth further: doing so contributes positively and significantly to TFP growth.

Acknowledgements We would like to thank the Editor and two anonymous referees for helpful and insightful comments. Responsibility for the information and views set out in this article lies entirely with the authors.

\section{Disclosure of potential conflicts of interest}

The authors declare that they have no conflict of interest.

\section{References}

Allen J, Liu Y (2007) Efficiency and economies of scale of large Canadian banks. Canadian Journal of Economics 40(1):225-244, DOI 10.1111/j.1365-2966.2007.00406.x, URL http://dx.doi.org/10. $1111 / j .1365-2966.2007 .00406 . x$

Amel D, Barnes C, Panetta F, Salleo C (2004) Consolidation and efficiency in the financial sector: A review of the international evidence. Journal of Banking \& Finance 28(10):2493 - 2519, DOI 10.1016/j.jbankfin.2003.10.013, URL http://www.sciencedirect.com/science/article/pii/ S0378426603002759

Arellano M, Honore B (2001) Panel Data Models: Some Recent Developments. In: Heckman JJ, Leamer E (eds) Handbook of Econometrics, vol 5, Amsterdam: North-Holand, chap 53, pp 3229-3290

Bai J (2009) Panel Data Models with Interactive Fixed Effects. Econometrica 77(4):1229-1279

Bauer P, Berger A, Humphrey D (1993) Efficiency and productivity growth in US banking. In: Fried H, Lovell C, S S (eds) The measurement of productive efficiency: Techniques and applications, Oxford University Press, New York, pp 386-413

Berger AN, Humphrey D (1994) Bank Scale Economies, Mergers, Concentration, and Efficiency: The US Experience. Center for Financial Institutions Working Papers

Berger AN, Humphrey DB (1992) Megamergers in banking and the use of cost efficiency as an antitrust defense. Antitrust Bull 37:541 
Berger AN, Mester LJ (1997) Inside the Black Box: What Explains Differences in the Efficiencies of Financial Institutions? Journal of Banking \& Finance 21(7):895 - 947

Berger AN, Mester LJ (2003) Explaining the Dramatic Changes in Performance of US banks: Technological Change, Deregulation, and Dynamic Changes in Competition. Journal of Financial Intermediation 12(1):57 - 95

Berger AN, Hanweck GA, Humphrey DB (1987) Competitive viability in banking: Scale, scope, and product mix economies. Journal of Monetary Economics 20(3):501 - 520, DOI 10.1016/0304-3932(87)90039-0, URL http://www.sciencedirect.com/science/article/pii/ 0304393287900390

Berger AN, Demsetz RS, Strahan PE (1999) The consolidation of the financial services industry: Causes, consequences, and implications for the future. Journal of Banking \& Finance 23(24):135 194, DOI 10.1016/S0378-4266(98)00125-3, URL http://www.sciencedirect.com/science/article/ $\mathrm{pii/S0378426698001253}$

Borts GH (1954) Increasing returns in the railway industry. The Journal of Political Economy pp 316-333

Boyd J, Heitz A (2012) The Social Costs and Benefits of Too-Big-To-Fail Banks: A "Bounding" Exercise. Tech. rep., University of Minnesota

Camacho FT, Menezes FM (2009) Access pricing and investment: a real options approach. Journal of Regulatory Economics 36(2):107-126

Chamberlain G (1984) Panel Data. In: Griliches Z, Intriligator M (eds) Handbook of Econometrics, vol 2, Amsterdam: North-Holand, chap 22, pp 1248-1318

Clark JA (1988) Economies of scale and scope at depository financial institutions: A review of the literature. Economic Review 73(8):17-33

Clark JA (1996) Economic Cost, Scale Efficiency, and Competitive Viability in Banking. Journal of Money, Credit and Banking 28(3):pp. 342-364, URL http://www.jstor.org/stable/2077979

Daniels KN, Tirtiroglu D (1998) Total Factor Productivity Growth in U.S. Commercial Banking for 1935-1991: A Latent Variable Approach Using the Kalman Filter. Journal of Financial Services Research 13:119-135, URL http://dx.doi.org/10.1023/A:1007922103037, 10.1023/A:1007922103037

Das A, Kumbhakar S (2012) Productivity and Efficiency Dynamics in Indian Banking: an Input Distance Function Approach Incorporating Quality of Inputs and Outputs. Journal of Applied Econometrics 27(2):205-234

Davies R, Tracey B (2014) Too Big to Be Efficient? The Impact of Implicit Subsidies on Estimates of Scale Economies for Banks. Journal of Money, Credit and Banking 46(s1):219-253, DOI 10.1111/ jmcb.12088, URL http://dx.doi.org/10.1111/jmcb.12088

Denny M, Fuss M, Waverman L (1979) Productivity Measurement in Regulated industries, Academic Press, chap The measurement and interpretation of total factor productivity in regulated industries, with an application to Canadian telecommunications, pp 179-212

DeYoung R (1991) The efficiencies defense and commercial bank merger regulation. Review of Industrial Organization 6(3):269-282, DOI 10.1007/BF00378126, URL http://dx.doi.org/10.1007/ BF00378126

DeYoung R (2010) Scale economies are a distraction. The Region 10(3):7, DOI 10.1007/BF00378126, URL http://dx.doi.org/10.1007/BF00378126

Diewert WE, Fox KJ (2008) On the estimation of returns to scale, technical progress and monopolistic markups. Journal of Econometrics 145(12):174 - 193, DOI 10.1016/j.jeconom.2008.05.002, URL http://www.sciencedirect.com/science/article/pii/S0304407608000584

Ellig J, Giberson M (1993) Scale, scope, and regulation in the Texas gas transmission industry. Journal of regulatory economics 5(1):79-90

Evanoff DD, Israilevich PR, Merris RC (1990) Relative price efficiency, technical change, and scale economies for large commercial banks. Journal of Regulatory Economics 2(3):281-298 
Evans L, Guthrie G (2006) Incentive regulation of prices when costs are sunk. Journal of Regulatory Economics 29(3):239-264

Farrell J, Shapiro C (2001) Scale economies and synergies in horizontal merger analysis. Antitrust Law Journal 68(3):685-710

Feldman R (2010) Size and regulatory reform in finance: important but difficult questions. The Region, Federal Reserve Bank of Minneapolis 10:7

Feng G, Serletis A (2009) Efficiency and productivity of the US banking industry, 1998-2005: evidence from the Fourier cost function satisfying global regularity conditions. Journal of Applied Econometrics 24(1):105-138

Feng G, Serletis A (2010) Efficiency, technical change, and returns to scale in large US banks: Panel data evidence from an output distance function satisfying theoretical regularity. Journal of Banking \& Finance 34(1):127 - 138, DOI 10.1016/j.jbankfin.2009.07.009, URL http://www.sciencedirect. com/science/article/pii/S0378426609001630

Feng G, Zhang X (2012) Productivity and efficiency at large and community banks in the US: A Bayesian true random effects stochastic distance frontier analysis. Journal of Banking \& Finance 36(6):1883-1895, DOI 10.1016/j.jbankfin.2012.02.008, URL http://www.sciencedirect.com/ science/article/pii/S0378426612000519

Foreman RD, Beauvais E (1999) Scale economies in cellular telephony: Size matters. Journal of Regulatory Economics 16(3):297-306

Fraquelli G, Piacenza M, Vannoni D (2005) Cost Savings From Generation and Distribution with an Application to Italian Electric Utilities*. Journal of regulatory economics 28(3):289-308

Gandhi P, Lustig H (Forthcoming) Size Anomalies in U.S. Bank Stock Returns. Journal of Finance pp 1-39, DOI DOI:10.1111/jofi.12235

Glass V, Stefanova SK (2012) Economies of scale for broadband in rural United States. Journal of Regulatory Economics 41(1):100-119

Greene W (2005a) Fixed and Random Effects in Stochastic Frontier Models. Journal of Productivity Analysis 23:7-32, 10.1007/s11123-004-8545-1

Greene W (2005b) Reconsidering heterogeneity in panel data estimators of the stochastic frontier model. Journal of Econometrics 126(2):269 - 303, DOI 10.1016/j.jeconom.2004.05.003, URL http: //www.sciencedirect.com/science/article/pii/S0304407604001137

Hardle W, Mammen E (1993) Comparing Nonparametric Versus Parametric Regression Fits. The Annals of Statistics 21(4):pp. 1926-1947, URL http://www.jstor.org/stable/2242322

Hayfield T, Racine JS (2008) Nonparametric Econometrics: The np Package. Journal of Statistical Software 27(5), URL http://www.jstatsoft.org/v27/i05/

Hughes J, Mester L (1998) Bank capitalization and cost: Evidence of scale economies in risk management and signaling. Review of Economics and Statistics 80(2):314-325

Hughes JP, Mester LJ (2010) Efficiency in Banking: Theory, Practice, and Evidence. In: Berger A, Molyneux P, Wilson J (eds) The Oxford Handbook of Banking, Oxford University Press, New York, chap 19, DOI 10.2139/ssrn.1092220

Hughes JP, Mester LJ (2013) Who said large banks don't experience scale economies? Evidence from a risk-return-driven cost function. Journal of Financial Intermediation 22(4):559 - 585, DOI http: //dx.doi.org/10.1016/j.jfi.2013.06.004, URL http://www.sciencedirect.com/science/article/pii/ S1042957313000296

Hughes JP, Lang W, Mester LJ, Moon CG (1996) Efficient Banking under Interstate Branching. Journal of Money, Credit and Banking 28(4):pp. 1045-1071, URL http://www.jstor.org/stable/ 2077940

Hughes JP, Lang W, Mester LJ, Moon CG (2000) Recovering Risky Technologies Using the Almost Ideal Demand System: An Application to U.S. Banking. Journal of Financial Services Research 18:5-27, URL http://dx.doi.org/10.1023/A : 1026554922476, 10.1023/A:1026554922476 
Hughes JP, Mester LJ, Moon CG (2001) Are scale economies in banking elusive or illusive?: Evidence obtained by incorporating capital structure and risk-taking into models of bank production. Journal of Banking \& Finance 25(12):2169 - 2208, DOI 10.1016/S0378-4266(01)00190-X, URL http://www . sciencedirect.com/science/article/pii/S037842660100190X

Humphrey D (1992) Flow versus stock indicators of banking output: effects on productivity and scale economy measurement. Journal of Financial Services Research 6(2):115-135

Humphrey DB (1991) Productivity in banking and effects from deregulation. Economic Review 1(Mar):16-28

Humphrey DB (1993) Cost and Technical Change: Effects from Bank Deregulation. Journal of Productivity Analysis 4(1/2):9 - 34, URL http://proxy.binghamton.edu/login?url=http://search. ebscohost. com/login. aspx?direct=true\&db=bth\&AN=16852575\&site=ehost-live

Hunter WC, Timme SG (1986) Technical Change, Organizational Form, and the Structure of Bank Production. Journal of Money, Credit and Banking 18(2):pp. 152-166, URL http://www. jstor.org/ stable/1992199

Hunter WC, Timme SG (1991) Technological Change in Large U.S. Commercial Banks. The Journal of Business 64(3):pp. 339-362, URL http://www.jstor.org/stable/2353094

Johnson S (2012) Tarullo Telegraphs Fed's Plans to Cap Bank Size. Bloomberg News' Column, URL http://www.bloomberg.com/news/2012-12-09/ tarullo-telegraphs-fed-s-plans-to-cap-bank-size.html

Kinne K (1998) The "efficiency defense" in the US American merger policy. Tech. rep., HWWA Discussion Paper

Kolasky WJ, Dick AR (2003) The merger guidelines and the integration of efficiencies into antitrust review of horizontal mergers. Antitrust Law Journal 71:207-251

Kumbhakar S, Lozano-Vivas A (2005) Deregulation and productivity: The case of Spanish banks. Journal of Regulatory Economics 27(3):331-351

Kumbhakar S, Sun K (2012) Estimation of TFP growth: a semiparametric smooth coefficient approach. Empirical Economics 43(1):1-24

Kumbhakar S, Lien G, Flaten O, Tveters R (2008) Impacts of Norwegian Milk Quotas on Output Growth: A Modified Distance Function Approach. Journal of Agricultural Economics 59(2):350 369, DOI 10.1111/j.1477-9552.2008.00154.x, URL http://dx.doi.org/10.1111/j.1477-9552.2008. 00154. $\mathrm{x}$

Kumbhakar SC, Wang D (2007) Economic reforms, efficiency and productivity in Chinese banking. Journal of Regulatory Economics 32(2):105-129

Lagerlof JN, Heidhues P (2005) On the desirability of an efficiency defense in merger control. International Journal of Industrial Organization 23(910):803 - 827, DOI http://dx. doi.org/10.1016/j.ijindorg.2005.08.005, URL http://www.sciencedirect.com/science/article/pii/ S0167718705001268

Laudati LL (1981) Note: Economies of Scale: Weighing Operating Efficiency when Enforcing Antitrust Law. Fordham Law Review 49:771-801

Li Q, Racine J (2007) Nonparametric econometrics: Theory and Practice. Princeton University Press

Li Q, Racine JS (2010) Smooth Varying-Coefficient Estimation and Inference for Qualitative and Quantitative Data. Econometric Theory 26(06):1607-1637, DOI 10.1017/S0266466609990739, URL http://dx.doi.org/10.1017/S0266466609990739, http://journals.cambridge.org/article_ S0266466609990739

Li Q, Huang CJ, Li D, Fu TT (2002) Semiparametric Smooth Coefficient Models. Journal of Business \& Economic Statistics 20(3):pp. 412-422, URL http://www.jstor.org/stable/1392126

Malikov E, Restrepo-Tobón D, Kumbhakar SC (2014) Estimation of banking technology under credit uncertainty. Empirical Economics Forthcoming:1-27, DOI 10.1007/s00181-014-0849-z, URL http: //dx.doi.org/10.1007/s00181-014-0849-z 
McAfee RP, Mialon HM, Williams MA (2004) What is a Barrier to Entry? American Economic Review 94(2):461-465, DOI 10.1257/0002828041302235

Mester LJ (1994) How efficient are third district banks? Business Review (Jan):1-3

Mester LJ (1996) A study of bank efficiency taking into account risk-preferences. Journal of Banking \& Finance 20(6):1025 - 1045, DOI 10.1016/0378-4266(95)00047-X, URL http://www.sciencedirect. com/science/article/pii/037842669500047X

Mester LJ (1997) Measuring efficiency at U.S. banks: Accounting for heterogeneity is important. European Journal of Operational Research 98(2):230 - 242, DOI 10.1016/S0377-2217(96)00344-X, URL http://www.sciencedirect.com/science/article/pii/S037722179600344X

Mukherjee K, Ray SC, Miller SM (2001) Productivity growth in large US commercial banks: The initial post-deregulation experience. Journal of Banking \& Finance 25(5):913 - 939, DOI 10.1016/S0378-4266(00)00103-5, URL http://www.sciencedirect.com/science/article/pii/ S0378426600001035

Nauges C, Van Den Berg C (2008) Economies of density, scale and scope in the water supply and sewerage sector: a study of four developing and transition economies. Journal of Regulatory Economics $34(2): 144-163$

Restrepo D, Kumbhakar S (2013) Profit efficiency of U.S. commercial banks: a decomposition. Working Paper EAFIT University 1-36(13-18):1

Restrepo-Tobón D, Kumbhakar S (2014) Nonparametric estimation of returns to scale using input distance functions: an application to large U.S. banks. Empirical Economics 48(1):143-168, DOI 10.1007/s00181-014-0831-9, URL http://dx.doi.org/10.1007/s00181-014-0831-9

Robinson P (1988) Root-N-consistent Semiparametric Regression. Econometrica: Journal of the Econometric Society 56(4):931-954

Rogers K (1998) Nontraditional Activities and The Efficiency of US Commercial Banks. Journal of Banking \& Finance 22(4):467-482

Schmalensee R (2004) Sunk costs and antitrust barriers to entry. American Economic Review 94(2):471-475

Sealey C, Lindley J (1977) Inputs, outputs, and a theory of production and cost at depository financial institutions. Journal of Finance 32(4):1251-1266

Semenick Alam IM (2001) A Nonparametric Approach for Assessing Productivity Dynamics of Large U.S. Banks. Journal of Money, Credit and Banking 33(1):pp. 121-139, URL http://www . jstor .org/ stable/2673875

Shaffer S (1994) A revenue-restricted cost study of 100 large banks. Applied Financial Economics 4(3):193-205, DOI 10.1080/758526900, URL http://www.tandfonline.com/doi/abs/10. 1080/758526900, http://www.tandfonline.com/doi/pdf/10.1080/758526900

Stern G, Feldman R (2009) Addressing TBTF by shrinking financial institutions: An initial assessment. Federal Reserve Bank of Minneapolis: The Region, June pp 8-13

Stiroh KJ (2000) How Did Bank Holding Companies Prosper in the 1990s? Journal of Banking \& Finance 24(11):1703 - 1745

Tirtiroglu D, Daniels KN, Tirtirogu E (2005) Deregulation, Intensity of Competition, Industry Evolution, and the Productivity Growth of U.S. Commercial Banks. Journal of Money, Credit and Banking 37(2):pp. 339-360, URL http://www.jstor.org/stable/3838930

Wang HJ, Ho CW (2010) Estimating fixed-effect panel stochastic frontier models by model transformation. Journal of Econometrics 157(2):286-296, DOI 10.1016/j.jeconom.2009.12.006, URL http://www.sciencedirect.com/science/article/pii/S0304407610000047

Wheelock DC, Wilson PW (1999) Technical Progress, Inefficiency, and Productivity Change in U.S. Banking, 1984-1993. Journal of Money, Credit and Banking 31(2):pp. 212-234, URL http://www . jstor.org/stable/2601230 
Wheelock DC, Wilson PW (2001) New evidence on returns to scale and product mix among U.S. commercial banks. Journal of Monetary Economics 47(3):653 - 674, DOI 10.1016/S0304-3932(01) 00059-9, URL http://www.sciencedirect.com/science/article/pii/S0304393201000599

Wheelock DC, Wilson PW (2011) Are credit unions too small? Review of Economics and Statistics 93(4):1343-1359

Wheelock DC, Wilson PW (2012) Do Large Banks Have Lower Costs? New Estimates of Returns to Scale for U.S. Banks. Journal of Money, Credit and Banking 44(1):171 - 199

Williamson OE (1968) Economies as an antitrust defense: The welfare tradeoffs. The American Economic Review 58(1):18-36

Williamson OE (1977) Economies as an antitrust defense revisited. In: Welfare aspects of industrial markets, vol 2, Springer, pp 237-271 
Tables and Figures

Table 1 Summary Statistics, 2001-2010

\begin{tabular}{|c|c|c|c|c|c|c|c|}
\hline \multirow[b]{2}{*}{ Variable } & \multirow[b]{2}{*}{ Mean } & \multirow[b]{2}{*}{ sd } & \multicolumn{5}{|c|}{ Percentiles } \\
\hline & & & $5^{t h}$ & $25^{t h}$ & $50^{t h}$ & $75^{t h}$ & $95^{t h}$ \\
\hline$\overline{Y_{1}}$ & 70,358 & $1,700,000$ & 81.50 & 655.7 & 4,532 & 46,077 & $137,000,000$ \\
\hline$Y_{2}$ & 360,000 & $5,390,000$ & 1,177 & 5,683 & 49,638 & 546,000 & $404,000,000$ \\
\hline$Y_{3}$ & 220,000 & $4,740,000$ & 713.5 & 2,953 & 17,131 & 166,000 & $348,000,000$ \\
\hline$Y_{4}$ & 291,000 & $7,950,000$ & 826.4 & 4,601 & 27,012 & 247,000 & $782,000,000$ \\
\hline$Y_{5}$ & 38,042 & $1,010,000$ & 95.62 & 308.0 & 1,595 & 17,445 & $89,500,000$ \\
\hline$X_{1}$ & 226 & 3,476 & 3.000 & 8.500 & 36.25 & 296.75 & 214,000 \\
\hline$X_{2}$ & 11,686 & 146,000 & 4.000 & 151.80 & 2,022 & 19,613 & $10,500,000$ \\
\hline$X_{3}$ & 290,000 & $6,670,000$ & 24.628 & 2,519 & 21,474 & 272,000 & $540,000,000$ \\
\hline$X_{4}$ & 26,307 & 247,000 & 56.084 & 1,757 & 10,096 & 53,636 & $20,000,000$ \\
\hline$X_{5}$ & 545,000 & $11,000,000$ & 1,025 & 10,929 & 50,047 & 585,000 & $763,000,000$ \\
\hline$W_{1}$ & 52.54 & 12.99 & 23.91 & 36.47 & 49.99 & 77.82 & 117.1 \\
\hline$W_{2}$ & 0.346 & 0.338 & 0.052 & 0.104 & 0.241 & 0.955 & 3.406 \\
\hline$W_{3}$ & 0.034 & 0.011 & 0.008 & 0.017 & 0.034 & 0.053 & 0.064 \\
\hline$W_{4}$ & 0.010 & 0.007 & 0.001 & 0.002 & 0.008 & 0.025 & 0.042 \\
\hline$W_{5}$ & 0.026 & 0.010 & 0.004 & 0.011 & 0.025 & 0.046 & 0.055 \\
\hline$R$ & 71,765 & $1,300,000$ & 234 & 1,792 & 8,290 & 78,874 & $83,600,000$ \\
\hline$R_{1}$ & 0.065 & 0.058 & 0.000 & 0.007 & 0.051 & 0.171 & 0.913 \\
\hline$R_{2}$ & 0.416 & 0.165 & 0.000 & 0.149 & 0.414 & 0.693 & 0.943 \\
\hline$R_{3}$ & 0.205 & 0.147 & 0.000 & 0.040 & 0.164 & 0.511 & 0.915 \\
\hline$R_{4}$ & 0.153 & 0.106 & 0.000 & 0.027 & 0.129 & 0.358 & 0.961 \\
\hline$R_{5}$ & 0.161 & 0.088 & 0.001 & 0.049 & 0.148 & 0.312 & 0.920 \\
\hline$C$ & 39,045 & 758,000 & 237 & 978 & 4,678 & 43,661 & $54,100,000$ \\
\hline$S_{1}$ & 0.413 & 0.108 & 0.026 & 0.247 & 0.407 & 0.599 & 0.877 \\
\hline$S_{2}$ & 0.103 & 0.041 & 0.001 & 0.046 & 0.099 & 0.177 & 0.393 \\
\hline$S_{3}$ & 0.166 & 0.089 & 0.000 & 0.046 & 0.154 & 0.326 & 0.907 \\
\hline$S_{4}$ & 0.026 & 0.028 & 0.000 & 0.002 & 0.017 & 0.078 & 0.447 \\
\hline$S_{5}$ & 0.292 & 0.104 & 0.011 & 0.131 & 0.285 & 0.473 & 0.958 \\
\hline$S Y_{1}$ & 0.058 & 0.053 & 0.000 & 0.006 & 0.045 & 0.153 & 0.879 \\
\hline$S Y_{2}$ & 0.458 & 0.173 & 0.000 & 0.169 & 0.460 & 0.736 & 0.946 \\
\hline$S Y_{3}$ & 0.187 & 0.115 & 0.000 & 0.046 & 0.161 & 0.416 & 0.931 \\
\hline$S Y_{4}$ & 0.281 & 0.152 & 0.002 & 0.074 & 0.257 & 0.567 & 0.960 \\
\hline$S Y_{5}$ & 0.016 & 0.009 & 0.001 & 0.008 & 0.015 & 0.029 & 0.275 \\
\hline$S Y_{123}$ & 0.703 & 0.152 & 0.024 & 0.418 & 0.726 & 0.910 & 0.991 \\
\hline$Z_{1}$ & 9.513 & 1.192 & 6.170 & 7.903 & 9.373 & 11.55 & 18.85 \\
\hline$Z_{2}$ & 0.059 & 0.065 & 0.000 & 0.008 & 0.040 & 0.166 & 0.882 \\
\hline$Z_{3}$ & 0.009 & 0.015 & 0.000 & 0.000 & 0.005 & 0.033 & 0.472 \\
\hline Tot. Assets & $1,050,000$ & $21,000,000$ & 5,888 & 25,382 & 115,000 & $1,080,000$ & $1,520,000,000$ \\
\hline
\end{tabular}

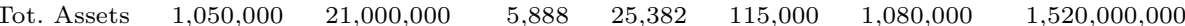

This table shows the average (Mean), standard deviation (sd), the median, and the 5 and 95 percentiles (p5 and p95, respectively). All nominal variables are measured in thousands of 2005 U.S. dollars. The data used for estimation include 60,868 year-bank observations for 7,473 different banks. The output variables are: household and individual loans $\left(Y_{1}\right)$, real estate loans $\left(Y_{2}\right)$, loans to business and other institutions $\left(Y_{3}\right)$, federal funds sold and securities purchased under agreements to resell $\left(Y_{4}\right)$, and other assets $\left(Y_{5}\right)$. The input variables are: labor quantity $\left(X_{1}\right)$, premises and fixed assets $\left(X_{2}\right)$, purchased funds $\left(X_{3}\right)$, interest-bearing transaction accounts $\left(X_{4}\right)$, and non-transaction accounts $\left(X_{5}\right)$. For each input $X_{j}$ its price, $W_{j}$, is computed by dividing total expenses by the corresponding input quantity. Rev is total revenues, and $R_{q}$ represents the revenue shares for each output category. Likewise, $S_{k}$ represents cost shares for each input category and $S Y_{q}$ represents output share for each output category. $S Y_{123}=\left(Y_{1}+Y_{2}+Y_{3}\right) /\left(Y_{1}+Y_{2}+Y_{3}+Y_{4}+Y_{5}\right) . Z_{1}$ is $\log$ of equity, $Z_{2}$ is a proxy for off-balance sheet activities (noninterest income over total income), and $Z_{3}$ equals nonperforming loans over total assets. 
Table 2 Estimated Functional Coefficients

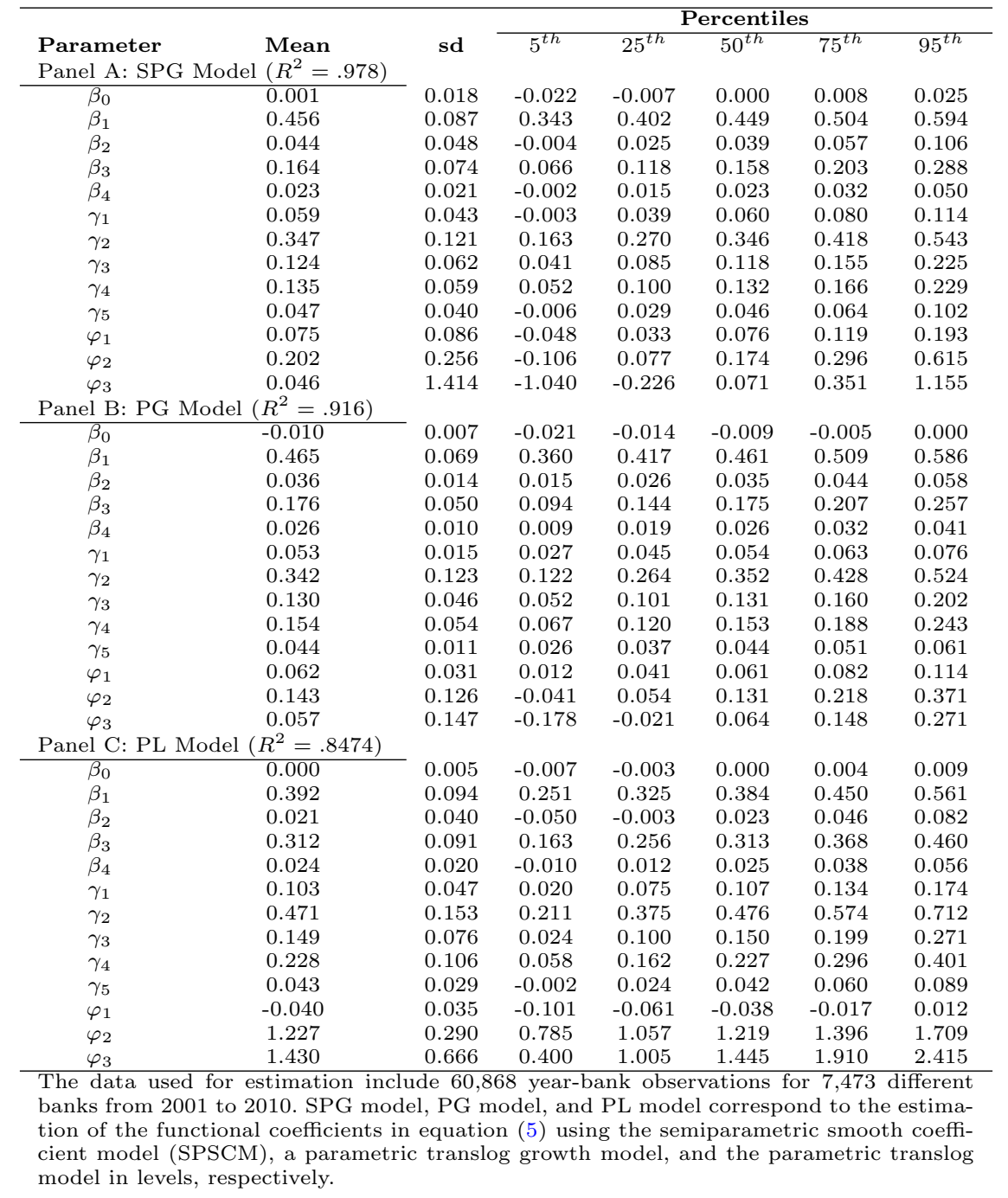


Table 3 Theoretical Monotonicity Restrictions

\begin{tabular}{lccccc}
\hline \multicolumn{5}{c}{ \% of observations that are non-decreasing in input prices } \\
\hline \multicolumn{7}{c}{$w_{1}$} & $w_{2}$ & $w_{3}$ & $w_{4}$ & $w_{5}$ \\
\hline SPG Model & $99.96 \%$ & $94.18 \%$ & $99.47 \%$ & $93.86 \%$ & $99.88 \%$ \\
PG Model & $100.00 \%$ & $99.90 \%$ & $99.97 \%$ & $99.45 \%$ & $100.00 \%$ \\
PL Model & $100.00 \%$ & $72.68 \%$ & $99.82 \%$ & $88.57 \%$ & $98.62 \%$ \\
\hline \multicolumn{5}{c}{ \% of observations that are non-decreasing in outputs } \\
\multicolumn{7}{c}{$y_{1}$} & $y_{2}$ & $y_{3}$ & $y_{4}$ & $y_{5}$ \\
\hline SPG Model & $94.39 \%$ & $99.69 \%$ & $98.87 \%$ & $99.39 \%$ & $93.74 \%$ \\
PG Model & $99.65 \%$ & $99.23 \%$ & $99.21 \%$ & $99.51 \%$ & $99.99 \%$ \\
PL Model & $97.52 \%$ & $99.60 \%$ & $97.09 \%$ & $98.12 \%$ & $93.98 \%$ \\
\hline This table shows the percentage of observations for which total \\
cost is non-decreasing in input prices and output quantities. The \\
data used for estimation include 60,868 year-bank observations for \\
7,473 different banks from 2001 to 2010. SPG model, PG model, \\
and PL model correspond to the estimation of the functional co- \\
efficients in equation (5) using the semiparametric smooth coeffi- \\
cient model (SPSCM), a parametric translog growth model, and \\
the parametric translog model in levels, respectively.
\end{tabular}


Table 4 Hypothesis testings for the coefficient estimates at the $5 \%$ level

\begin{tabular}{|c|c|c|c|c|c|}
\hline & $\beta_{0}$ & $\beta_{1}$ & $\beta_{2}$ & $\beta_{3}$ & $\beta_{4}$ \\
\hline SPG Model & & & & & \\
\hline Significantly positive & $24.53 \%$ & $99.93 \%$ & $83.21 \%$ & $98.67 \%$ & $82.54 \%$ \\
\hline Insignificant & $48.82 \%$ & $0.03 \%$ & $14.20 \%$ & $1.02 \%$ & $14.83 \%$ \\
\hline Significantly negative & $26.66 \%$ & $0.03 \%$ & $2.60 \%$ & $0.31 \%$ & $2.63 \%$ \\
\hline \multicolumn{6}{|l|}{ PG Model } \\
\hline Significantly positive & $1.04 \%$ & $100.00 \%$ & $98.33 \%$ & $99.88 \%$ & $96.89 \%$ \\
\hline Insignificant & $12.71 \%$ & $0.00 \%$ & $1.67 \%$ & $0.11 \%$ & $3.09 \%$ \\
\hline Significantly negative & $86.26 \%$ & $0.00 \%$ & $0.00 \%$ & $0.01 \%$ & $0.02 \%$ \\
\hline \multicolumn{6}{|l|}{ PL Model } \\
\hline Significantly positive & $30.23 \%$ & $100.00 \%$ & $63.79 \%$ & $99.57 \%$ & $79.00 \%$ \\
\hline Insignificant & $46.20 \%$ & $0.00 \%$ & $16.31 \%$ & $0.37 \%$ & $15.59 \%$ \\
\hline \multirow{2}{*}{ Significantly negative } & $23.57 \%$ & $0.00 \%$ & $19.90 \%$ & $0.07 \%$ & $5.40 \%$ \\
\hline & $\gamma_{1}$ & $\gamma_{2}$ & $\gamma_{3}$ & $\gamma_{4}$ & $\gamma_{5}$ \\
\hline \multicolumn{6}{|l|}{ SPG Model } \\
\hline Significantly positive & $87.58 \%$ & $99.39 \%$ & $97.77 \%$ & $98.72 \%$ & $82.39 \%$ \\
\hline Insignificant & $9.57 \%$ & $0.40 \%$ & $1.57 \%$ & $0.90 \%$ & $14.87 \%$ \\
\hline Significantly negative & $2.85 \%$ & $0.21 \%$ & $0.66 \%$ & $0.38 \%$ & $2.75 \%$ \\
\hline \multicolumn{6}{|l|}{ PG Model } \\
\hline Significantly positive & $97.34 \%$ & $98.83 \%$ & $98.60 \%$ & $99.19 \%$ & $99.21 \%$ \\
\hline Insignificant & $0.74 \%$ & $0.96 \%$ & $0.57 \%$ & $0.79 \%$ & $11.46 \%$ \\
\hline Significantly negative & $0.02 \%$ & $0.44 \%$ & $0.44 \%$ & $0.24 \%$ & $0.00 \%$ \\
\hline \multicolumn{6}{|l|}{ PL Model } \\
\hline Significantly positive & $96.49 \%$ & $99.47 \%$ & $95.98 \%$ & $97.72 \%$ & $85.10 \%$ \\
\hline Insignificant & $1.81 \%$ & $0.25 \%$ & $2.00 \%$ & $0.81 \%$ & $13.21 \%$ \\
\hline \multirow[t]{2}{*}{ Significantly negative } & $1.69 \%$ & $0.28 \%$ & $2.02 \%$ & $1.47 \%$ & $1.69 \%$ \\
\hline & $\phi_{1}$ & $\phi_{2}$ & $\phi_{3}$ & & \\
\hline \multicolumn{6}{|l|}{ SPG Model } \\
\hline Significantly positive & $69.26 \%$ & $63.10 \%$ & $20.94 \%$ & & \\
\hline Insignificant & $25.89 \%$ & $32.98 \%$ & $64.83 \%$ & & \\
\hline Significantly negative & $4.85 \%$ & $3.92 \%$ & $14.23 \%$ & & \\
\hline \multicolumn{6}{|l|}{ PG Model } \\
\hline Significantly positive & $88.34 \%$ & $50.01 \%$ & $10.46 \%$ & & \\
\hline Insignificant & $11.46 \%$ & $49.37 \%$ & $87.72 \%$ & & \\
\hline Significantly negative & $0.21 \%$ & $0.62 \%$ & $1.82 \%$ & & \\
\hline \multicolumn{6}{|l|}{ PL Model } \\
\hline Significantly positive & $1.37 \%$ & $99.58 \%$ & $94.57 \%$ & & \\
\hline Insignificant & $29.50 \%$ & $0.38 \%$ & $4.74 \%$ & & \\
\hline Significantly negative & $69.13 \%$ & $0.04 \%$ & $0.69 \%$ & & \\
\hline \multicolumn{6}{|c|}{$\begin{array}{l}\text { This table shows the percentage of observations for which the indi- } \\
\text { cated functional coefficient is significantly positive, insignificant, or } \\
\text { significantly negative for each model. The data used for estimation } \\
\text { include } 60,868 \text { year-bank observations for } 7,473 \text { different banks from } \\
2001 \text { to } 2010 \text {. SPG model, PG model, and PL model correspond to the } \\
\text { estimation of the functional coefficients in equation (5) using the semi- } \\
\text { parametric smooth coefficient model (SPSCM), a parametric translog } \\
\text { growth model, and the parametric translog model in levels, respec- } \\
\text { tively. }\end{array}$} \\
\hline
\end{tabular}


Table 5 Summary Statistics for Returns to Scale Estimates by Bank Size

\begin{tabular}{|c|c|c|c|c|c|c|c|}
\hline \multirow{2}{*}{$\begin{array}{c}\text { Bank size } \\
\text { Panel A: SPG Model }\end{array}$} & \multirow[b]{2}{*}{ Mean } & \multirow[b]{2}{*}{ sd } & \multicolumn{5}{|c|}{ Percentiles } \\
\hline & & & $5^{t h}$ & $25^{t h}$ & $50^{t h}$ & $75^{t h}$ & $95^{t h}$ \\
\hline & 1.127 & 0.276 & 0.799 & 0.959 & 1.086 & 1.237 & 1.577 \\
\hline $\mathrm{Big}$ & 1.180 & 0.234 & 0.903 & 1.044 & 1.144 & 1.266 & 1.581 \\
\hline Medium & 1.335 & 0.164 & 1.130 & 1.239 & 1.311 & 1.399 & 1.626 \\
\hline Small & 1.561 & 0.263 & 1.263 & 1.389 & 1.512 & 1.670 & 2.020 \\
\hline All & 1.425 & 0.247 & 1.135 & 1.274 & 1.375 & 1.532 & 1.860 \\
\hline Panel B: PG Model & & & & & & & \\
\hline TOP100 & 1.011 & 0.087 & 0.859 & 0.957 & 1.019 & 1.065 & 1.144 \\
\hline Big & 1.103 & 0.095 & 0.920 & 1.052 & 1.112 & 1.162 & 1.240 \\
\hline Medium & 1.323 & 0.098 & 1.177 & 1.255 & 1.317 & 1.381 & 1.491 \\
\hline Small & 1.541 & 0.141 & 1.356 & 1.436 & 1.516 & 1.621 & 1.810 \\
\hline All & 1.403 & 0.174 & 1.152 & 1.287 & 1.386 & 1.502 & 1.722 \\
\hline Panel C: PL Model & & & & & & & \\
\hline TOP100 & 1.036 & 0.050 & 0.964 & 1.002 & 1.031 & 1.064 & 1.132 \\
\hline Big & 1.022 & 0.043 & 0.963 & 0.993 & 1.016 & 1.043 & 1.100 \\
\hline Medium & 1.008 & 0.034 & 0.953 & 0.986 & 1.007 & 1.028 & 1.064 \\
\hline Small & 1.009 & 0.035 & 0.953 & 0.986 & 1.009 & 1.032 & 1.067 \\
\hline All & 1.009 & 0.035 & 0.954 & 0.987 & 1.008 & 1.031 & 1.067 \\
\hline
\end{tabular}
include 60,868 year-bank observations for 7,473 different banks from 2001 to 2010 . SPG model, PG model, and PL model correspond to RTS estimates computed after estimating (5) using the semiparametric smooth coefficient model (SPSCM), a parametric translog growth model, and the parametric translog model in levels, respectively. TOP100 corresponds to RTS estimates for the 100 biggest banks. Banks size categories are: Big (assets $>\$ 1$ billion), medium (\$100 million $<$ assets $<\$ 1$ billion), and small (assets $<\$ 100$ million) banks. 
Table 6 Percentage of Big Banks with IRTS, DRTS, or CRTS.

\begin{tabular}{|c|c|c|c|c|c|c|c|c|c|c|}
\hline \multicolumn{11}{|c|}{ Medium and Small Banks } \\
\hline & & \multicolumn{3}{|c|}{ SPG Model } & \multicolumn{3}{|c|}{ PG Model } & \multicolumn{3}{|c|}{ PL Model } \\
\hline Year & $\mathbf{N}$ & IRTS & DRTS & CRTS & IRTS & DRTS & CRTS & IRTS & DRTS & CRTS \\
\hline 2002 & 5021 & $95 \%$ & $0 \%$ & $4 \%$ & $100 \%$ & $0 \%$ & $0 \%$ & $14 \%$ & $32 \%$ & $54 \%$ \\
\hline 2003 & 6181 & $99 \%$ & $0 \%$ & $1 \%$ & $100 \%$ & $0 \%$ & $0 \%$ & $29 \%$ & $19 \%$ & $52 \%$ \\
\hline 2004 & 6175 & $99 \%$ & $0 \%$ & $1 \%$ & $100 \%$ & $0 \%$ & $0 \%$ & $35 \%$ & $15 \%$ & $50 \%$ \\
\hline 2005 & 6066 & $99 \%$ & $0 \%$ & $1 \%$ & $100 \%$ & $0 \%$ & $0 \%$ & $28 \%$ & $21 \%$ & $51 \%$ \\
\hline 2006 & 5852 & $98 \%$ & $0 \%$ & $1 \%$ & $100 \%$ & $0 \%$ & $0 \%$ & $19 \%$ & $30 \%$ & $51 \%$ \\
\hline 2007 & 5554 & $99 \%$ & $0 \%$ & $1 \%$ & $100 \%$ & $0 \%$ & $0 \%$ & $15 \%$ & $35 \%$ & $50 \%$ \\
\hline 2008 & 5161 & $99 \%$ & $0 \%$ & $1 \%$ & $100 \%$ & $0 \%$ & $0 \%$ & $29 \%$ & $20 \%$ & $51 \%$ \\
\hline 2009 & 4718 & $99 \%$ & $0 \%$ & $1 \%$ & $100 \%$ & $0 \%$ & $0 \%$ & $48 \%$ & $7 \%$ & $45 \%$ \\
\hline 2010 & 4364 & $98 \%$ & $0 \%$ & $2 \%$ & $100 \%$ & $0 \%$ & $0 \%$ & $65 \%$ & $3 \%$ & $33 \%$ \\
\hline Avg & 5455 & $98 \%$ & $0 \%$ & $2 \%$ & $100 \%$ & $0 \%$ & $0 \%$ & $31 \%$ & $20 \%$ & $49 \%$ \\
\hline \multicolumn{11}{|c|}{ Big Banks } \\
\hline & & \multicolumn{3}{|c|}{ SPG Model } & \multicolumn{3}{|c|}{ PG Model } & \multicolumn{3}{|c|}{ PL Model } \\
\hline Year & $\mathbf{N}$ & IRTS & DRTS & CRTS & IRTS & DRTS & CRTS & IRTS & DRTS & CRTS \\
\hline 2002 & 260 & $68 \%$ & $23 \%$ & $8 \%$ & $70 \%$ & $6 \%$ & $24 \%$ & $23 \%$ & $9 \%$ & $68 \%$ \\
\hline 2003 & 309 & $83 \%$ & $12 \%$ & $5 \%$ & $75 \%$ & $5 \%$ & $20 \%$ & $41 \%$ & $5 \%$ & $54 \%$ \\
\hline 2004 & 340 & $85 \%$ & $7 \%$ & $8 \%$ & $76 \%$ & $5 \%$ & $19 \%$ & $39 \%$ & $8 \%$ & $54 \%$ \\
\hline 2005 & 355 & $70 \%$ & $12 \%$ & $18 \%$ & $73 \%$ & $6 \%$ & $21 \%$ & $27 \%$ & $17 \%$ & $55 \%$ \\
\hline 2006 & 364 & $59 \%$ & $18 \%$ & $23 \%$ & $69 \%$ & $7 \%$ & $24 \%$ & $14 \%$ & $31 \%$ & $55 \%$ \\
\hline 2007 & 349 & $65 \%$ & $13 \%$ & $22 \%$ & $68 \%$ & $6 \%$ & $26 \%$ & $10 \%$ & $39 \%$ & $51 \%$ \\
\hline 2008 & 323 & $80 \%$ & $11 \%$ & $9 \%$ & $72 \%$ & $7 \%$ & $21 \%$ & $24 \%$ & $21 \%$ & $54 \%$ \\
\hline 2009 & 306 & $79 \%$ & $10 \%$ & $10 \%$ & $76 \%$ & $5 \%$ & $19 \%$ & $49 \%$ & $8 \%$ & $43 \%$ \\
\hline 2010 & 268 & $72 \%$ & $14 \%$ & $14 \%$ & $82 \%$ & $3 \%$ & $15 \%$ & $65 \%$ & $3 \%$ & $32 \%$ \\
\hline Avg & 319 & $73 \%$ & $13 \%$ & $13 \%$ & $74 \%$ & $5 \%$ & $21 \%$ & $32 \%$ & $16 \%$ & $52 \%$ \\
\hline \multicolumn{11}{|c|}{ Top 100 Banks } \\
\hline & & \multicolumn{3}{|c|}{ SPG Model } & \multicolumn{3}{|c|}{ PG Model } & \multicolumn{3}{|c|}{ PL Model } \\
\hline Year & $\mathbf{N}$ & IRTS & DRTS & CRTS & IRTS & DRTS & CRTS & IRTS & DRTS & CRTS \\
\hline 2002 & 100 & $39 \%$ & $51 \%$ & $10 \%$ & $25 \%$ & $15 \%$ & $60 \%$ & $30 \%$ & $1 \%$ & $69 \%$ \\
\hline 2003 & 100 & $71 \%$ & $25 \%$ & $4 \%$ & $26 \%$ & $15 \%$ & $59 \%$ & $55 \%$ & $1 \%$ & $44 \%$ \\
\hline 2004 & 100 & $84 \%$ & $15 \%$ & $1 \%$ & $22 \%$ & $17 \%$ & $61 \%$ & $49 \%$ & $3 \%$ & $48 \%$ \\
\hline 2005 & 100 & $73 \%$ & $18 \%$ & $9 \%$ & $12 \%$ & $22 \%$ & $66 \%$ & $30 \%$ & $9 \%$ & $61 \%$ \\
\hline 2006 & 100 & $60 \%$ & $30 \%$ & $10 \%$ & $11 \%$ & $25 \%$ & $64 \%$ & $22 \%$ & $21 \%$ & $57 \%$ \\
\hline 2007 & 100 & $51 \%$ & $29 \%$ & $20 \%$ & $14 \%$ & $22 \%$ & $64 \%$ & $15 \%$ & $29 \%$ & $56 \%$ \\
\hline 2008 & 100 & $71 \%$ & $24 \%$ & $5 \%$ & $18 \%$ & $21 \%$ & $61 \%$ & $30 \%$ & $17 \%$ & $53 \%$ \\
\hline 2009 & 100 & $70 \%$ & $21 \%$ & $9 \%$ & $29 \%$ & $14 \%$ & $57 \%$ & $52 \%$ & $6 \%$ & $42 \%$ \\
\hline 2010 & 100 & $70 \%$ & $17 \%$ & $13 \%$ & $52 \%$ & $9 \%$ & $39 \%$ & $65 \%$ & $2 \%$ & $33 \%$ \\
\hline Avg & 100 & $65 \%$ & $26 \%$ & $9 \%$ & $23 \%$ & $18 \%$ & $59 \%$ & $39 \%$ & $10 \%$ & $51 \%$ \\
\hline
\end{tabular}

This table shows the percentage of observations with statistically significant increasing (IRTS), decreasing (DRTS), and constant (CRTS) RTS. A specific RTS estimate indicates IRTS, DRTS, or CRTS if its 95\% confidence interval lies entirely above, entirely below, or includes one, respectively. The data used for estimation include 60,868 year-bank observations for 7,473 different banks from 2001 to 2010 . SPG model, PG model, and PL model correspond to RTS estimates computed after estimating (5) using the semiparametric smooth coefficient model (SPSCM), a parametric translog growth model, and the parametric translog model in levels, respectively. TOP100 corresponds to RTS estimates for the 100 biggest banks. Banks size categories are: Big (assets $>\$ 1$ billion), medium ( $\$ 100$ million $<$ assets $<\$ 1$ billion), and small (assets $<\$ 100$ million) banks. 
Table 8 TFP Components

\begin{tabular}{|c|c|c|c|c|c|c|c|}
\hline \multirow[b]{2}{*}{ Variable } & \multirow[b]{2}{*}{ Mean } & \multirow[b]{2}{*}{ sd } & \multicolumn{5}{|c|}{ Percentiles } \\
\hline & & & $5^{t h}$ & $25^{t h}$ & $50^{t h}$ & $75^{t h}$ & $95^{t h}$ \\
\hline TFP Divisia & 0.031 & 0.083 & -0.077 & -0.009 & 0.026 & 0.064 & 0.150 \\
\hline Panel A: SPG Model & & & & & & & \\
\hline TFP Growth & 0.031 & 0.076 & -0.057 & -0.005 & 0.024 & 0.058 & 0.140 \\
\hline Scale & 0.022 & 0.070 & -0.053 & -0.009 & 0.013 & 0.041 & 0.120 \\
\hline $\mathrm{TC}$ & -0.001 & 0.018 & -0.025 & -0.008 & 0.000 & 0.007 & 0.022 \\
\hline Allocative & 0.017 & 0.042 & -0.040 & -0.005 & 0.013 & 0.037 & 0.087 \\
\hline Exogenous & -0.007 & 0.025 & -0.036 & -0.011 & -0.004 & 0.000 & 0.014 \\
\hline Panel B: PG Model & & & & & & & \\
\hline TFP Growth & 0.031 & 0.071 & -0.058 & -0.005 & 0.024 & 0.059 & 0.139 \\
\hline Scale & 0.018 & 0.063 & -0.052 & -0.009 & 0.012 & 0.037 & 0.108 \\
\hline $\mathrm{TC}$ & 0.010 & 0.007 & 0.000 & 0.005 & 0.009 & 0.014 & 0.021 \\
\hline Allocative & 0.007 & 0.038 & -0.049 & -0.013 & 0.006 & 0.026 & 0.068 \\
\hline Exogenous & -0.004 & 0.012 & -0.020 & -0.007 & -0.003 & -0.000 & 0.007 \\
\hline Panel C: PL Model & & & & & & & \\
\hline TFP Growth & 0.011 & 0.084 & -0.106 & -0.030 & 0.008 & 0.050 & 0.135 \\
\hline Scale & 0.002 & 0.051 & -0.066 & -0.017 & 0.003 & 0.022 & 0.065 \\
\hline TC & -0.000 & 0.005 & -0.009 & -0.004 & -0.000 & 0.003 & 0.007 \\
\hline Allocative & 0.008 & 0.057 & -0.081 & -0.021 & 0.008 & 0.038 & 0.097 \\
\hline Exogenous & 0.002 & 0.043 & -0.046 & -0.013 & -0.000 & 0.012 & 0.052 \\
\hline
\end{tabular}

SPG, PG, and PL models. 
Table 9 TFP Components Variance Contribution

\begin{tabular}{|c|c|c|c|c|c|c|}
\hline TFP Component & $\begin{array}{l}\text { Semipartial } \\
\text { correlation }\end{array}$ & $\begin{array}{l}\text { Common } \\
\text { variance }\end{array}$ & $\begin{array}{l}\text { Bootstrap } \\
\text { Std. Errors }\end{array}$ & P-value & {$[95 \%$} & Conf. Interval] \\
\hline SPG Model & & & & & & \\
\hline Technical Change & 0.218 & 0.048 & 0.006 & 0.000 & 0.036 & 0.059 \\
\hline Allocative & 0.524 & 0.275 & 0.007 & 0.000 & 0.261 & 0.289 \\
\hline Scale & 0.895 & 0.801 & 0.006 & 0.000 & 0.789 & 0.812 \\
\hline $\begin{array}{l}\text { Exogeneous } \\
P G \text { Model }\end{array}$ & 0.326 & 0.106 & 0.010 & 0.000 & 0.087 & 0.126 \\
\hline Technical Change & 0.090 & 0.008 & 0.001 & 0.000 & 0.006 & 0.010 \\
\hline Allocative & 0.527 & 0.278 & 0.008 & 0.000 & 0.262 & 0.294 \\
\hline Scale & 0.864 & 0.746 & 0.008 & 0.000 & 0.731 & 0.761 \\
\hline Exogeneous & 0.165 & 0.027 & 0.005 & 0.000 & 0.018 & 0.037 \\
\hline PL Model & & & & & & \\
\hline Technical Change & 0.060 & 0.004 & 0.001 & 0.000 & 0.002 & 0.005 \\
\hline Allocative & 0.668 & 0.446 & 0.013 & 0.000 & 0.421 & 0.471 \\
\hline Scale & 0.610 & 0.372 & 0.015 & 0.000 & 0.343 & 0.401 \\
\hline Exogeneous & 0.505 & 0.255 & 0.015 & 0.000 & 0.227 & 0.284 \\
\hline
\end{tabular}

SPG, PG, and PL models. 

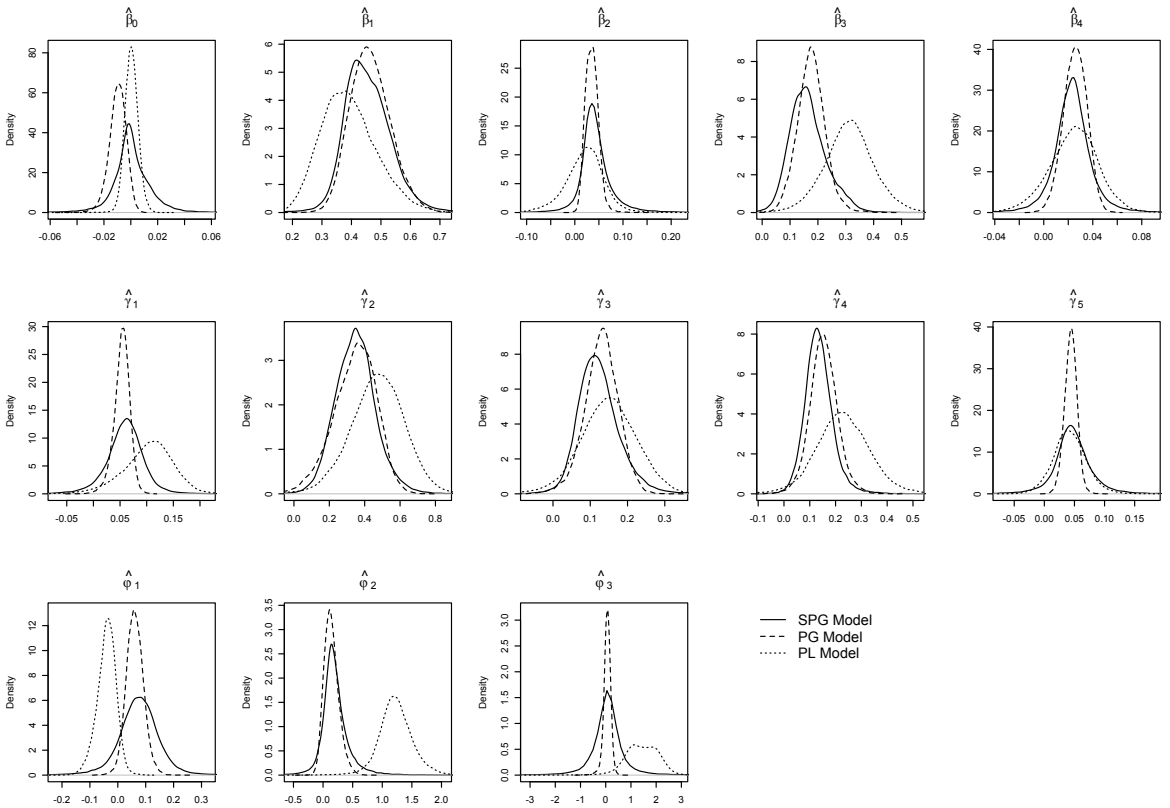

\section{- SPG Model PL Model}

Fig. 1 Density plots of estimated functional coefficients.
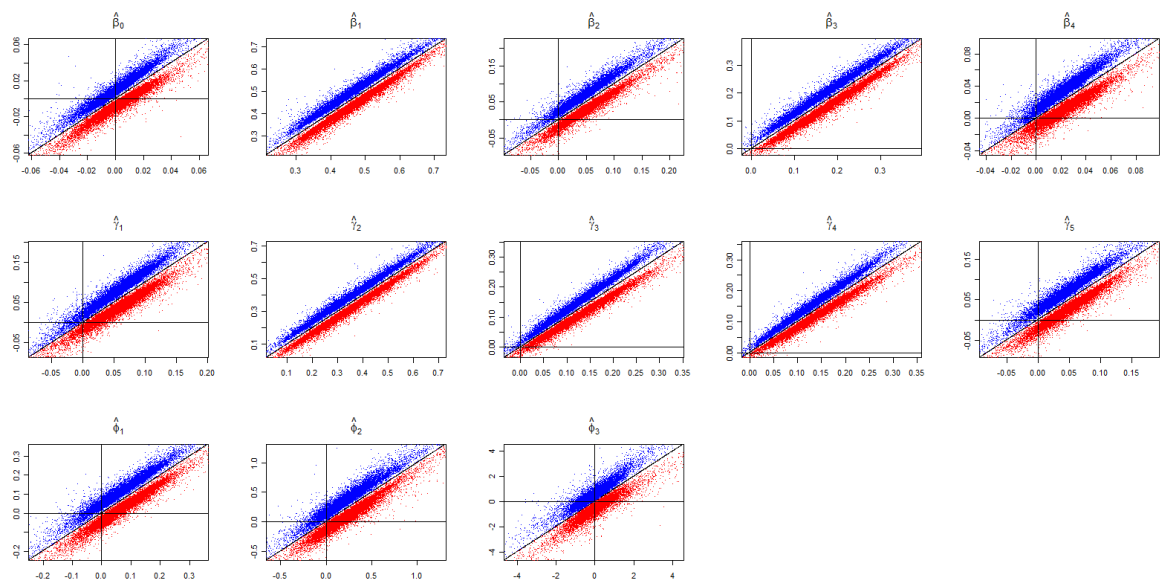

Fig. 2 Confidence intervals for bootstrapped standard errors of SPG model. 


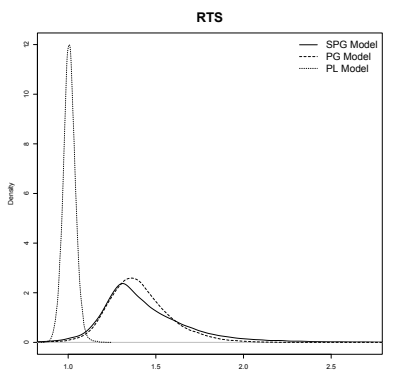

Fig. 3 Density plots for RTS estimates for all banks.
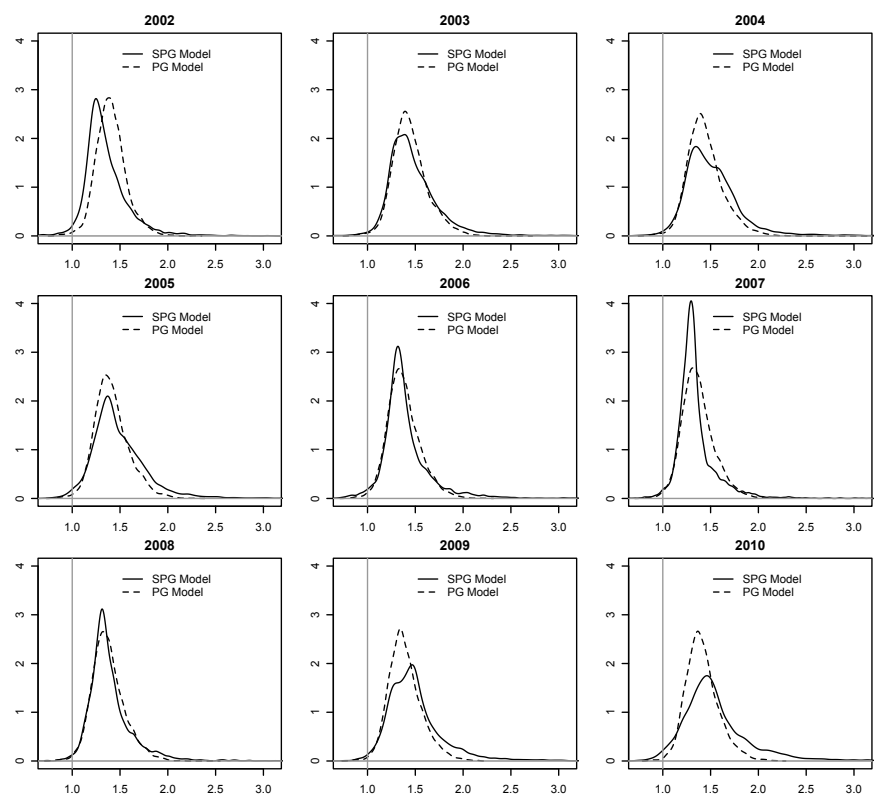

Fig. 4 RTS estimates over time. 

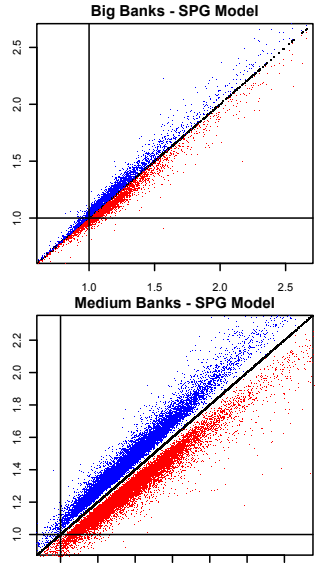

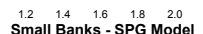

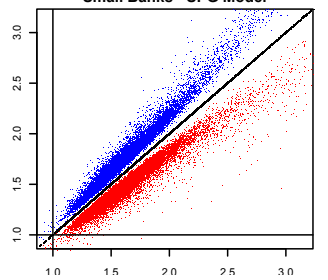

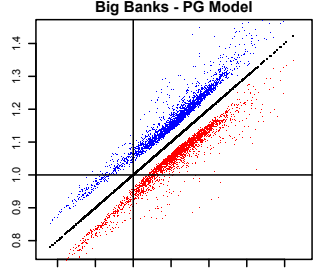

0.8 \begin{tabular}{ccccc}
0.9 & 1.0 & 1.1 & 1.2 & 1.3 \\
Medium Banks - PG Model & 1.4 \\
\hline
\end{tabular}

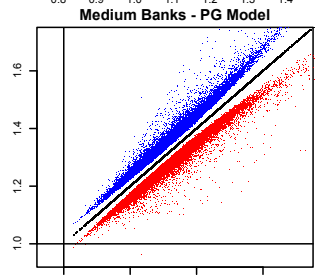

$1.0 \quad 1.2 \quad \stackrel{1.4}{1.4}{ }^{1.6}$

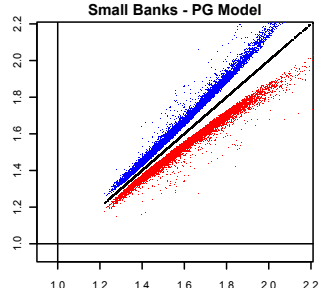

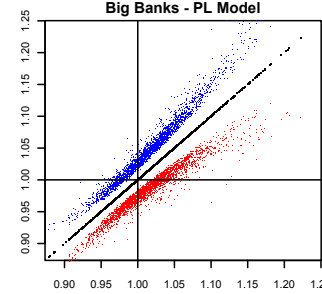
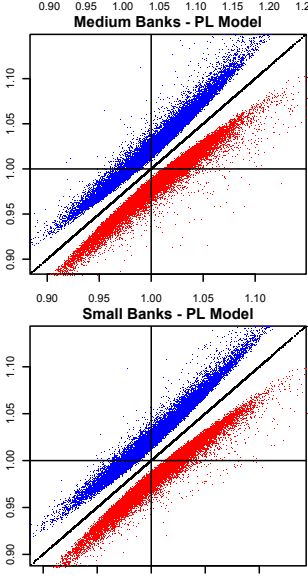

Fig. 5 Confidence intervals for RTS estimates for each model

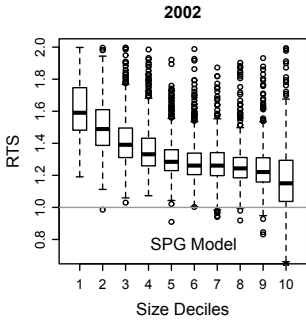

2002

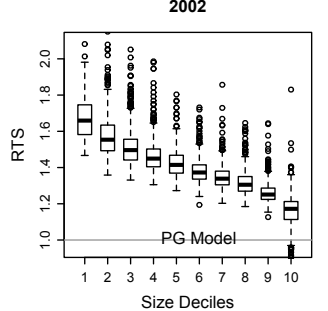

2006

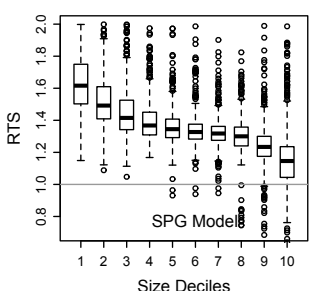

2006

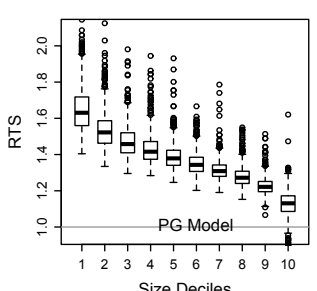

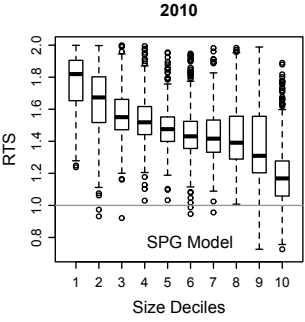

2010

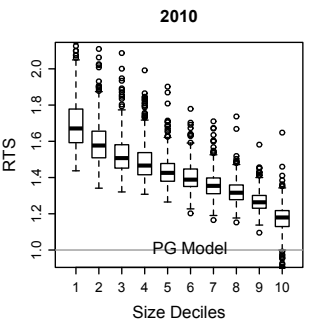

Fig. 6 RTS estimates from SPG and PG models by bank size deciles based on total assets. 

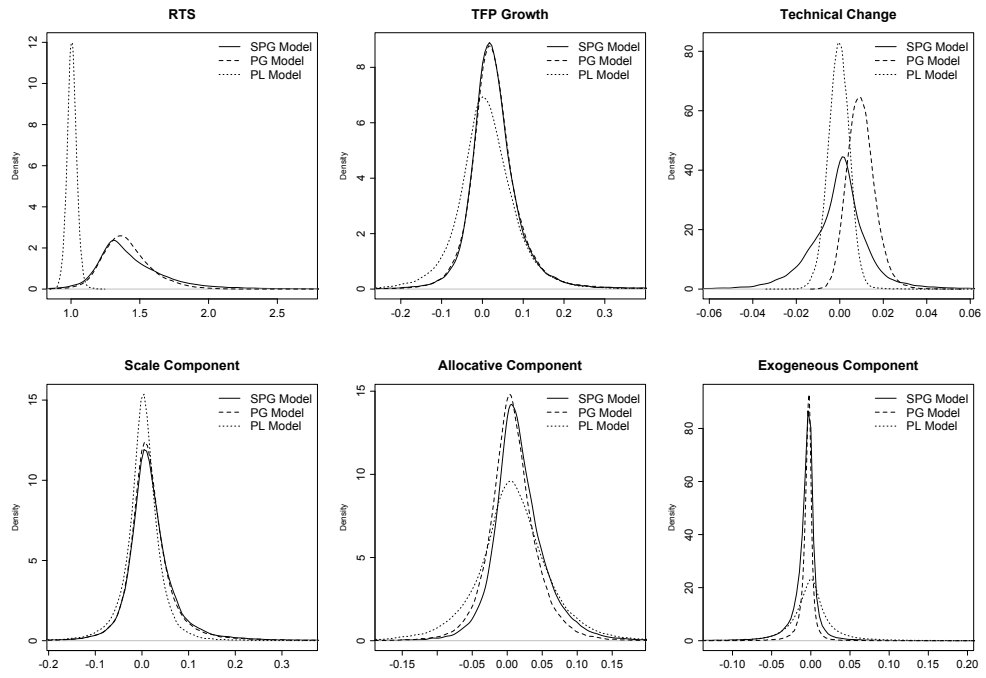

Fig. 7 Density plots for RTS and TFP components.
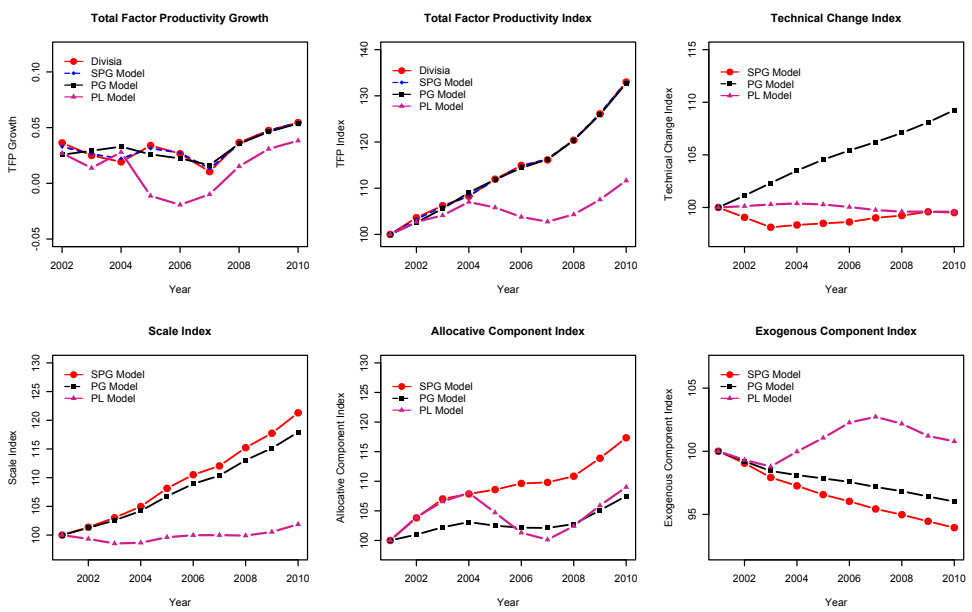

Fig. 8 TFP Growth and TFP Indexes over time. 


\section{Appendix A TFP Growth Decomposition}

Starting with the standard definition of TFP change in (7) and adding $T \dot{F} P$ to both sides of (5) we have:

$$
T \dot{F} P+\beta_{0}(\cdot)+\sum_{k=1}^{K-1} \beta_{k}(\cdot) \dot{\widetilde{W}}_{k}+\sum_{q=1}^{Q} \gamma_{q}(\cdot) \dot{Y}_{q}+\sum_{p=1}^{P} \varphi_{p}(\cdot) \nabla_{t} Z_{p}+u \equiv \dot{\widetilde{C}}+\sum_{q=1}^{Q} R_{q} \dot{Y}_{q}-\sum_{k=1}^{K} S_{k} \dot{X}_{k}
$$

Using the definitions $\dot{\widetilde{C}}=\dot{C}-\dot{W}_{K}$ and $\dot{C}=\sum_{k=1}^{K} S_{k} \dot{W}_{k}+\sum_{k=1}^{K} S_{k} \dot{X}_{k}$, the right-hand-side of (A-1) can be expressed as:

$$
\dot{\widetilde{C}}+\sum_{q=1}^{Q} R_{q} \dot{Y}_{q}-\sum_{k=1}^{K} S_{k} \dot{X}_{k} \equiv \sum_{k=1}^{K} S_{k} \dot{W}_{k}+\sum_{q=1}^{Q} R_{q} \dot{Y}_{q}-\dot{W}_{K}
$$

Since $\sum_{k=1}^{K} S_{k}=1, \dot{W}_{k}=\dot{\widetilde{W}}_{k}+\dot{W}_{K}, \forall k=1, \ldots, K-1$, and $\widetilde{\widetilde{W}}_{K}=0$,

$$
\sum_{k=1}^{K} S_{k} \dot{W}_{k}+\sum_{q=1}^{Q} R_{q} \dot{Y}_{q}-\dot{W}_{K} \equiv \sum_{k=1}^{K-1} S_{k} \dot{\tilde{W}}_{k}+\sum_{q=1}^{Q} R_{q} \dot{Y}_{q}
$$

Using this result, the relationship in (A-1) can be expressed as:

$$
T \dot{F} P \equiv-\beta_{0}(\cdot)+\sum_{q=1}^{Q}\left(R_{q}-\gamma_{q}(\cdot)\right) \dot{Y}_{q}+\sum_{k=1}^{K-1}\left(S_{k}-\beta_{k}(\cdot)\right) \tilde{\widetilde{W}}_{k}-\sum_{p=1}^{P} \varphi_{p}(\cdot) \nabla_{t} Z_{p}-u
$$

\section{Appendix B Model Specifications and Estimation}

Following Li et al (2002) and $\mathrm{Li}$ and Racine (2007), the local-constant estimator for $\Psi(z)$ in 9 is expressed as:

$$
\hat{\Psi}(z)=\left[\sum_{i=1}^{N} \sum_{t=1}^{T} \mathcal{X}_{i t} \mathcal{X}_{i t}^{\prime} \mathcal{K}\left(\frac{\mathcal{Z}_{i t}-z}{h}\right)\right]^{-1} \sum_{i=1}^{N} \sum_{t=1}^{T} \mathcal{X}_{i t} \mathcal{Y}_{i t} \mathcal{K}\left(\frac{\mathcal{Z}_{i t}-z}{h}\right)
$$

where $N$ and $T$ denotes number of banks and time periods, respectively, $h$ is a $(K+Q+P)$ vector with each element a selected bandwidth for each $z$ variable and $\mathcal{K}(\cdot)$ is the product Gaussian kernel function. ${ }^{34}$

Note that if the kernel function is absent, then the SPSC estimator reduces to its OLS counterpart. The SPSC model also nests the partially linear model proposed by Robinson (1988) as a special case, which makes only the intercept an unknown smooth function of the $\mathcal{Z}$ variables.

Following Li and Racine (2010), we employ the most commonly used least-squares cross-validation (LSCV) method, which is a fully automatic data-driven approach, to select the bandwidth vector $h$, i.e.,

$$
C V_{l c}(h)=\min _{h} \sum_{i=1}^{N} \sum_{t=1}^{T}\left[\mathcal{Y}_{i t}-\mathcal{X}_{i t}^{\prime} \hat{\Psi}_{-i t}\left(\mathcal{Z}_{i t}\right)\right]^{2} M\left(\mathcal{Z}_{i t}\right)
$$

where $C V_{l c}(h)$ determines the cross-validation bandwidth vector $h$ for local constant estimator, $\mathcal{X}_{i t}^{\prime} \hat{\Psi}_{-i t}\left(\mathcal{Z}_{i t}\right)$ is the leave-one-out local-constant kernel conditional mean, and $0 \leq M(\cdot) \leq 1$ is a weight function that serves to avoid difficulties caused by dividing by zero. Unlike other methods proposed in the recent literature (e.g. Feng and Serletis, 2010 and Wheelock and Wilson, 2011) the SPG model can be easily estimated using widely available statistical software. For instance, the bandwidths for the $\mathcal{Z}$ variables and the smooth coefficients can be estimated using the $N P$ package in $\mathrm{R}$ (Hayfield and Racine 2008). ${ }^{35}$

34 Explicitly, the kernel function is written as:

$$
\mathcal{K}(\cdot)=\prod_{l=1}^{K+Q+P} \frac{1}{\sqrt{2 \pi}} \exp \left(-\frac{1}{2}\left(\frac{\mathcal{Z}_{l i t}-z_{l}}{h_{l}}\right)^{2}\right)
$$

35 We use the functions npscoefbw and npscoef with their default values. To decrease the estimation computational time, we set the optimization options to "nmulti $=1 "$, "optim.abstol $=0.000001 "$, and "optim.reltol $=$ sqrt $(0.000001)$ ". 
Now, assuming that $f(\cdot)$ in $(3)$ is translog, the estimating equation for the PL model is:

$$
\begin{aligned}
f(\cdot)= & \alpha_{0}+\sum_{k=1}^{K-1} \theta_{k} \ln \widetilde{W}_{k}+\frac{1}{2} \sum_{k=1}^{K-1} \sum_{m=1}^{K-1} \theta_{k m} \ln \widetilde{W}_{k} \ln \widetilde{W}_{m}+\sum_{q=1}^{Q} \alpha_{q} \ln Y_{q}+\frac{1}{2} \sum_{q=1}^{Q} \sum_{o=1}^{Q} \alpha_{q o} \ln Y_{q} \ln Y_{o} \\
& +\sum_{q=1}^{Q} \sum_{k=1}^{K-1} \delta_{q k} \ln Y_{q} \ln \widetilde{W}_{k}+\alpha_{t} t+\frac{1}{2} \alpha_{t t} t^{2}+\sum_{q=1}^{Q} \lambda_{q t} \ln Y_{q} t+\sum_{k=1}^{K-1} \delta_{k t} \ln \widetilde{W}_{k} t+\sum_{p=1}^{P} \phi_{p} Z_{p} \\
& +\frac{1}{2} \sum_{p=1}^{P} \sum_{l=1}^{P} \phi_{p l} Z_{p} Z_{l}+\sum_{p=1}^{P} \sum_{k=1}^{K-1} \rho_{p k} Z_{p} \ln \widetilde{W}_{k}+\sum_{p=1}^{P} \sum_{q=1}^{Q} \tau_{p q} Z_{p} \ln Y_{q}+\sum_{p=1}^{P} \phi_{p t} Z_{p} t+u
\end{aligned}
$$

After estimating (A-7), the functional coefficients for the PL model are computed using:

$$
\begin{aligned}
\frac{\partial f}{\partial \ln \widetilde{W}_{k}} & =\beta_{k}(\cdot)=\theta_{k}+\sum_{m=1}^{K-1} \theta_{k m} \ln \widetilde{W}_{m}+\sum_{q=1}^{Q} \delta_{q k} \ln Y_{q}+\delta_{k t} t+\sum_{p=1}^{P} \rho_{p k} Z_{p}, \forall k=1, \ldots, K-1 \\
\frac{\partial f}{\partial \ln Y_{q}} & =\gamma_{q}(\cdot)=\alpha_{q}+\sum_{o=1}^{Q} \alpha_{q o} \ln Y_{o}+\sum_{k=1}^{K-1} \delta_{q k} \ln \widetilde{W}_{k}+\lambda_{q t} t+\sum_{p=1}^{P} \tau_{p q} Z_{p}, \forall q=1, \ldots, Q \\
\frac{\partial f}{\partial Z_{p}} & =\varphi_{p}(\cdot)=\phi_{p}+\sum_{l=1}^{P} \phi_{p l} Z_{l}+\sum_{k=1}^{K-1} \rho_{p k} \ln \widetilde{W}_{k}+\sum_{q=1}^{Q} \tau_{p q} \ln Y_{q}+\phi_{p t} t, \forall p=1, \ldots, P \\
\frac{\partial f}{\partial t} & =\beta_{0}(\cdot)=\alpha_{t}+\alpha_{t t} t+\sum_{q=1}^{Q} \lambda_{q t} \ln Y_{q}+\sum_{k=1}^{K-1} \delta_{k t} \ln \widetilde{W}_{k}+\sum_{p=1}^{P} \phi_{p t} Z_{p}
\end{aligned}
$$

Plugging (A-8)-(A-11) into (5) gives:

$$
\begin{aligned}
\dot{\tilde{C}}= & {\left[\alpha_{t}+\alpha_{t t} t+\sum_{q=1}^{Q} \lambda_{q t} \ln Y_{q}+\sum_{k=1}^{K-1} \delta_{k t} \ln \widetilde{W}_{k}+\sum_{p=1}^{P} \phi_{p t} Z_{p}\right] } \\
& +\sum_{k=1}^{K-1}\left[\theta_{k}+\sum_{m=1}^{K-1} \theta_{k m} \ln \widetilde{W}_{m}+\sum_{q=1}^{Q} \delta_{q k} \ln Y_{q}+\delta_{k t} t+\sum_{p=1}^{P} \rho_{p k} Z_{p}\right] \dot{\widetilde{W}}_{k} \\
& +\sum_{q=1}^{Q}\left[\alpha_{q}+\sum_{o=1}^{Q} \alpha_{q o} \ln Y_{o}+\sum_{k=1}^{K-1} \delta_{q k} \ln \widetilde{W}_{k}+\lambda_{q t} t+\sum_{p=1}^{P} \tau_{p q} Z_{p}\right] \dot{Y}_{q} \\
& +\sum_{p=1}^{P}\left[\phi_{p}+\sum_{l=1}^{P} \phi_{p l} Z_{l}+\sum_{k=1}^{K-1} \rho_{p k} \ln \widetilde{W}_{k}+\sum_{q=1}^{Q} \tau_{p q} \ln Y_{q}+\phi_{p t} t\right] \nabla_{t} Z_{p}+u
\end{aligned}
$$

Rearranging (A-12) gives the estimating equation for the PG model as follows:

$$
\begin{aligned}
\dot{\widetilde{C}}= & \alpha_{t}+\alpha_{t t} t+\sum_{k=1}^{K-1} \theta_{k} \dot{\tilde{W}}_{k}+\sum_{k=1}^{K-1} \sum_{m=1}^{K-1} \theta_{k m} \ln \widetilde{W}_{m} \dot{\vec{W}}_{k}+\sum_{q=1}^{Q} \alpha_{q} \dot{Y}_{q}+\sum_{q=1}^{Q} \sum_{o=1}^{Q} \alpha_{q o} \ln Y_{o} \dot{Y}_{q} \\
& +\sum_{p=1}^{P} \phi_{p} \nabla_{t} Z_{p}+\sum_{p=1}^{P} \sum_{l=1}^{P} \phi_{p l} Z_{l} \nabla_{t} Z_{p}+\sum_{q=1}^{Q} \lambda_{q t}\left(\ln Y_{q}+t \dot{Y}_{q}\right)+\sum_{k=1}^{K-1} \delta_{k t}\left(\ln \widetilde{W}_{k}+t \dot{\bar{W}}_{k}\right) \\
& +\sum_{p=1}^{P} \phi_{p t}\left(Z_{p}+t \nabla_{t} Z_{p}\right)+\sum_{k=1}^{K-1} \sum_{q=1}^{Q} \delta_{q k}\left(\ln Y_{q} \dot{\tilde{W}}_{k}+\ln \widetilde{W}_{k} \dot{Y}_{q}\right) \\
& +\sum_{k=1}^{K-1} \sum_{p=1}^{P} \rho_{p k}\left(Z_{p} \dot{\tilde{W}}_{k}+\ln \widetilde{W}_{k} \nabla_{t} Z_{p}\right)+\sum_{q=1}^{Q} \sum_{p=1}^{P} \tau_{p q}\left(Z_{p} \dot{Y}_{q}+\ln Y_{q} \nabla_{t} Z_{p}\right)+u
\end{aligned}
$$

After estimating (A-13), we compute the functional coefficients for the PG model using (A-8)-(A-11). 